\title{
Selective magnetic GMA based potential sorbents for molybdenum and rhenium sorption
}

\author{
Bojana M. Marković ${ }^{\mathrm{a}}$, Zorica M. Vuković ${ }^{\mathrm{b}}$, Vojislav V. Spasojević ${ }^{\mathrm{c}}$, Vladan B. Kusigerski ${ }^{\mathrm{c}}$, \\ Vladimir B. Pavlović d ${ }^{\text {, Antonije E. Onjia }}{ }^{c}$, Aleksandra B. Nastasović ${ }^{\text {a, * }}$ \\ a University of Belgrade, Institute of Chemistry Technology and Metallurgy, Department of Chemistry, Njegoševa 12, Belgrade, Serbia \\ ${ }^{\mathrm{b}}$ University of Belgrade, Institute of Chemistry Technology and Metallurgy, Department of Catalysis and Chemical Engineering, Njegoševa 12, Belgrade, \\ Serbia \\ ${ }^{c}$ University of Belgrade, Vinča Institute of Nuclear Sciences, P.O. Box 522, Belgrade, Serbia \\ d University of Belgrade, Faculty of Agriculture, Department of Mathematics and Physics, Nemanjina 6, Belgrade, Serbia
}

\section{A R T I C L E I N F O}

\section{Article history:}

Received 20 October 2016

Received in revised form

29 December 2016

Accepted 10 February 2017

Available online 14 February 2017

\section{Keywords:}

Magnetic macroporous copolymer

Diethylene triamine

$\mathrm{Mo}(\mathrm{VI})$ and $\mathrm{Re}(\mathrm{VII})$ sorption

\begin{abstract}
A B S T R A C T
Magnetic macroporous crosslinked copolymer glycidyl methacrylate (GMA) and ethylene glycol dimethacrylate (EGDMA) samples with different magnetite content were prepared by suspension copolymerization and functionalized with diethylene triamine. Samples were characterized by elemental analysis, mercury porosimetry, Fourier transform infrared spectroscopy (FTIR) analysis, scanning electron microscopy with energy-dispersive X-ray spectroscopy, transmission electron microscopy, SQUID magnetometry and X-ray photoelectron spectroscopy (XPS). The selected amino-functionalized sample was tested as a potential sorbent for the $\mathrm{Mo}(\mathrm{VI})$ and $\mathrm{Re}(\mathrm{VII})$ oxyanions from aqueous solutions. The influence of $\mathrm{pH}$, ionic strength and possible interfering of cations and anions was investigated. Equilibrium data were analyzed with Langmuir, Freundlich and Tempkin adsorption isotherm models. Sorption studies were carried out in a batch competitive experiments, in the $\mathrm{pH}$ range $1-8$, at $298 \mathrm{~K}$. Obtained results indicate that $92 \%$ of $\operatorname{Re}(\mathrm{VII})$ and $98 \%$ of $\mathrm{Mo}(\mathrm{VI})$ were sorbed at $\mathrm{pH} 2$.
\end{abstract}

() 2017 Elsevier B.V. All rights reserved.

\section{Introduction}

Molybdenum (Mo) is a transition metal that occurs in the range of oxidation states from +2 to +6 with the predominance of $\mathrm{Mo}$ (IV) and $\mathrm{Mo}(\mathrm{VI})$ species. In aqueous environment, Mo exists mainly as molybdate and/or other molybdenum polyanions, depending on the solution $\mathrm{pH}$ and the initial metal concentration [1]. Elevated molybdenum levels can cause serious health problems, anemia, liver and kidney abnormalities, bone and joint deformities, sterility, etc. [2].

Rhenium (Re) as a rare metal with high melting point, superior high-temperature strength and room-temperature ductility is an excellent choice for many applications demanding hightemperature, corrosion and wear resistance [3,4]. Re is widely used for high temperature superalloy productions, preparation of bimetallic catalysts for chemical and petrochemical industry,

\footnotetext{
* Corresponding author.

E-mail addresses: anastaso@chem.bg.ac.rs, anastasovic@yahoo.com (A.B. Nastasović).
}

thermocouples, etc. [3,5]. However, rhenium has no mineable ore naturally and invariably exists in rocks, pegmatites, and especially in molybdenites [4]. It is especially difficult to separate rhenium from molybdenum in an actual aqueous solution because of their similar ionic radius and anion species (mainly $\mathrm{MoO}_{4}{ }^{2-}$ and $\mathrm{ReO}_{4}{ }^{-}$) $[6,7]$. Recovery and separation of rhenium from molybdenite or industrial wastewater has become an urgent problem to be solved and is of great importance from an economical point of view.

Several methods of separating molybdenum and rhenium have been described in the literature, like ion exchange, precipitation, adsorption and solvent extraction [8]. Among them, adsorption is accepted as one of the most effective and economic method for wastewater treatment [4,7-9].

The iron oxide nanoparticles are increasingly applied for heavy metals removal from wastewaters since they exhibit excellent adsorption properties and can be easily separated using magnetic field [10-12]. Their drawbacks like small particle size, excessive pressure drops and coaggregation observed in flow-through systems could be avoided by supporting magnetite nanoparticles on polymers. Magnetic polymer microspheres combining a polymer 
and inorganic magnetic nanoparticles have been successfully used as carriers for enzyme immobilization, protein purification [13], separation of toxic and radioactive pollutants [14], etc.

Glycidyl methacrylate (GMA) based copolymers have versatile applications due to the presence of epoxy groups which offers numerous functionalization possibilities in mild reaction conditions. Amino-functionalized macroporous crosslinked copolymers of GMA and ethylene glycol dimethacrylate (EGDMA), PGME, prepared by suspension copolymerization in the shape of regular beads and specific pore size [15] have been utilized as matrix for enzyme attachment [16], sorbents for removal of textile dyes [17], radionuclides [18], precious and heavy metals, etc. [19-21].

In this paper the variation of the magnetite content on the porosity parameters, morphology and magnetic properties of magnetic macroporous PGME copolymer (mPGME) synthesized by suspension copolymerization was studied. The sample with the higher magnetite content was functionalized with diethylene triamine and evaluated as a potential $\mathrm{Mo}(\mathrm{VI})$ and $\mathrm{Re}(\mathrm{VII})$ sorbent from their binary solutions. To our best knowledge, this type of macroporous and magnetic amino-functionalized copolymer was not used for simultaneous $\mathrm{Mo}(\mathrm{VI})$ and $\operatorname{Re}(\mathrm{VII})$ ions separation. In this study, the influence of $\mathrm{pH}$, ionic strength, as well as the effect of coexisting cations $\left(\mathrm{Ni}^{2+}, \mathrm{Cd}^{2+}\right.$ and $\left.\mathrm{Cu}^{2+}\right)$ and anions $\left(\mathrm{Cl}^{-}, \mathrm{NO}^{3-}\right.$ and $\mathrm{SO}_{4}^{2-}$ ) on $\mathrm{Mo}(\mathrm{VI})$ and $\mathrm{Re}(\mathrm{VII})$ oxyanion sorption on PGME-deta was investigated. The Langmuir, Freundlich and Tempkin adsorption isotherm models were used to fit the experimental equilibrium data. Also, selectivity of mPGME-deta for $\operatorname{Re}(\mathrm{VII})$ sorption was studied at different contact time and Re/Mo ratio. In order to elucidate mechanism of $\mathrm{Mo}(\mathrm{VI})$ and $\mathrm{Re}(\mathrm{VII})$ oxyanion sorption, the Fourier transform infrared spectroscopy (FTIR) analysis and X-ray photoelectron spectroscopy (XPS) were used. The surface morphology of mPGME before and after metal ions sorption was investigated by scanning energy-dispersive X-ray spectroscopy (SEM-EDX).

\section{Experimental}

\subsection{Materials and reagents}

All the chemicals used for copolymer synthesis were analytical grade products and used as received. Glycidyl methacrylate (GMA), diethylene triamine, 2,2'-azobisiso-butyronitrile (AIBN), cyclohexanol and 1-tetradecanol were purchased from Merck (Germany). Ethylene glycol dimethacrylate (EGDMA) and magnetite (iron(II,III) oxide, nanopowder, $<50 \mathrm{~nm}$ particle size (TEM), $\geq 98 \%$ trace metals basis) were obtained from Sigma-Aldrich (Germany). Poly(N-vinyl pyrrolidone) (PVP, Kollidone 90) was purchased from BASF (Germany).

Molybdenum and rhenium stock solutions were prepared by dissolving reagent grade $\left(\mathrm{NH}_{4}\right) \mathrm{Mo}_{7} \mathrm{O}_{24} \cdot 4 \mathrm{H}_{2} \mathrm{O}$ and $\mathrm{NaReO}_{4}$ (SigmaAldrich, Germany) in deionized water (Milli-Q Millipore, $18 \mathrm{M} \Omega \mathrm{cm}^{-1}$ conductivity). The $\mathrm{pH}$ values of the working solutions were adjusted by adding of appropriate amounts of $1 \mathrm{M} \mathrm{HCl}$ and $1 \mathrm{M} \mathrm{NaOH}$. All solutions for the investigation of the effect of coexisting cations $\left(\mathrm{NiCl}_{2} \cdot 6 \mathrm{H}_{2} \mathrm{O}, \mathrm{CdCl}_{2}\right.$ and $\left.\mathrm{CuCl}_{2} \cdot 2 \cdot \mathrm{H}_{2} \mathrm{O}\right)$ and anions $\left(\mathrm{NaCl}, \mathrm{NaNO}_{3}\right.$ and $\mathrm{Na}_{2} \mathrm{SO}_{4}$ ) were prepared with deionized water (Milli-Q) and reagent-grade chemicals. The solutions of different concentrations used in various experiments were obtained by diluting the stock solutions.

\subsection{Preparation of $\mathrm{MPGME}$}

Two magnetic macroporous mPGME samples with different magnetite content ( 2 and 10 mass\%) in the reaction mixture were prepared by a radical suspension copolymerization (samples
2MAG-SGE60 and 10MAG-SGE60). Reaction mixtures consisted of the monomer phase suspended in the aqueous phase $(225.0 \mathrm{ml}$ of deionized water and $2.25 \mathrm{~g}$ of PVP). The monomer phase contained monomer mixture (29.2 g GMA and 19.5 g EGDMA), AIBN as an initiator $(0.5 \mathrm{~g})$, inert component ( $51.0 \mathrm{~g}$ of cyclohexanol and $12.8 \mathrm{~g}$ of tetradecanol) and magnetite $\left(\mathrm{Fe}_{3} \mathrm{O}_{4}\right)$ nanoparticles $(1.2 \mathrm{~g}$ for sample 2MAG-SGE60 and $4.8 \mathrm{~g}$ for sample 10MAG-SGE60). The aqueous phase was placed in polymerization reactor and heated to $70{ }^{\circ} \mathrm{C}$. The monomer phase was sonicated for about $30 \mathrm{~min}$ at $300 /$ $600 \mathrm{~W}$ within an ultrasonic water bath (Sonic $12 \mathrm{GT}$ ). The resulting mixture was dropped into polymerization reactor. The content of reactor was stirred at $300 \mathrm{rpm}$ during the monomer addition and heating was started. The copolymerization was carried out under nitrogen atmosphere at $75{ }^{\circ} \mathrm{C}$ for $2 \mathrm{~h}$ and at $80{ }^{\circ} \mathrm{C}$ for $2 \mathrm{~h}$ with a stirring rate of $250 \mathrm{rpm}$. After the reaction, the magnetic copolymer particles were washed with water and ethanol, kept in ethanol for $12 \mathrm{~h}$ and dried in vacuum oven at $50^{\circ} \mathrm{C}$.

\subsection{Functionalization of $m P G M E$ with diethylene triamine}

Sample 10MAG-SGE60 (particles with diameters in the range $0.15-0.30 \mathrm{~mm}$ ) was amino-functionalized as follows: $7.2 \mathrm{~g}$ of mPGME, $31.4 \mathrm{~g}$ of diethylene triamine and $350 \mathrm{~cm}^{3}$ of toluene was left at room temperature for $24 \mathrm{~h}$ and then heated at $80^{\circ} \mathrm{C}$ for $6 \mathrm{~h}$ with a stirring rate of $250 \mathrm{rpm}$ in a round bottom flask equipped with a mechanical stirrer and a reflux condenser. The aminofunctionalized sample was filtered, washed with ethanol, dried in vacuum oven for $24 \mathrm{~h}$ at $40{ }^{\circ} \mathrm{C}$ and labeled as 10MAG-SGE60-deta.

\subsection{Instrumentation and characterization}

Elemental analysis $(\mathrm{C}, \mathrm{H}, \mathrm{N})$ was performed by Vario EL III device (GmbH Hanau Instruments). Elemental composition was calculated from multiple determinations of elemental analysis within $\pm 0.2 \%$ agreement. Fourier transform infrared (FTIR) spectra were taken in ATR mode using a Nicolet 380 spectrometer. The scanning electron microscopy (SEM) micrographs were obtained on JEOL JSM-6460LV instrument (Tokyo, Japan). Samples were coated with gold in a high-vacuum evaporator. The energy dispersive spectroscopic (EDS) analysis was performed on Jeol JSM 5800 instrument. Pore size distributions were determined by a high pressure mercury intrusion porosimeter Carlo Erba Porosimeter 2000 (Washington, USA, software Milestone 200). The porosity parameters, i.e. the values of specific pore volume, $V_{s}$, and pore diameter which corresponds to half of pore volume, $D_{V / 2}$, were read from the pore size distribution curves determined by mercury porosimetry (Carlo Erba 2000, software Milestone 200), while the specific surface area, $S_{S, H g}$, was calculated as the sum of incremental specific surface areas from the pore size distribution curves as described in the literature [22]. Field dependance of isothermal magnetization $\mathrm{M}(\mathrm{H})$ at room temperature was measured on a SQUID-based commercial magnetometer Quantum Design MPMS-XL-5, in the applied DC fields up to $5 \mathrm{~T}$. Microstructural (morphological) characterization of selected samples was performed on a transmission electron microscope (TEM) JEM-1400. Mo(VI) and Re(VII) concentrations were determined using inductively coupled plasma optical emission spectrometry ICP-OES (Perkin Elmer, Model ICP 400).

XPS analysis was carried out on a SPECS customized UHV surface analysis system containing sputter ion gun, PHOIBOS 100 spectrometer for energy analysis, dual anode $\mathrm{Al} / \mathrm{Ag}$ monochromatic source and electron flood gun. XPS spectra were taken using monochromatic Al $\mathrm{K} \alpha$ line (photon energy of $1486.74 \mathrm{eV}$ ) in FAT 40 mode with energy step of $0.5 \mathrm{eV}$ and dwell time of $0.2 \mathrm{~s}$ (survey spectra) i.e. in FAT 20 mode with energy step of $0.1 \mathrm{eV}$ and dwell time of $1 \mathrm{~s}$ (high resolution spectra). 
The points of zero charge ( $\mathrm{pH}$ Pzc values) of selected samples were determined by the $\mathrm{pH}$ drift method [23]. For this purpose, the $\mathrm{pH}$ of test solutions $\left(20 \mathrm{~cm}^{3}\right.$ of $0.01 \mathrm{M} \mathrm{NaCl}$ in a series of Erlenmeyer flasks) was adjusted in the range between 2 and 12 using $0.1 \mathrm{M}$ $\mathrm{NaOH}$ and $0.1 \mathrm{M} \mathrm{HCl}$. The initial $\mathrm{pH}$ of the solutions $\left(\mathrm{pH}_{\mathrm{i}}\right)$ was determined and $50.0 \mathrm{mg}$ of the 10MAG-SGE60 and 10MAG-SGE60deta were added to each of the flasks and equilibrated for $24 \mathrm{~h}$. The final $\mathrm{pH}$ values of the solutions $\left(\mathrm{pH}_{\mathrm{f}}\right)$ were measured and plotted against the initial $\mathrm{pH}\left(\mathrm{pH}_{\mathrm{i}}\right)$. The $\mathrm{pH}$ at which the curve crosses $\mathrm{pH}_{\mathrm{i}}=\mathrm{pH}_{\mathrm{f}}$ line was taken as $\mathrm{pHpzc}$ [24]. $\mathrm{pH}$ was measured by Hanna HI $2210 \mathrm{pH}$ meter calibrated before every measure.

For determination of the amino groups content, $100 \mathrm{mg}$ of 10MAG-SGE60-deta was immersed in $5.2 \mathrm{~cm}^{3} 0.1 \mathrm{M} \mathrm{HCl}$ solution for $24 \mathrm{~h}$. After this period $2 \mathrm{~cm}^{3}$ of the solution was taken and the excess of acid was titrated with $0.052 \mathrm{M} \mathrm{NaOH}$ in the presence of phenolphthalein solution until the solution turned violet [25]. The content of amino groups, $C_{A G}\left(\mathrm{mmol} \mathrm{g}^{-1}\right)$ was calculated from Ref. [26]:

$C_{A G}=\frac{\left(C_{1} V_{1}-2 \cdot C_{2} V_{2}\right)}{m}$

where: $C_{1}$ is the initial $\mathrm{HCl}$ concentration $(0.105 \mathrm{M}), V_{1}$ is the initial volume of the $\mathrm{HCl}$ solution $\left(5.2 \mathrm{~cm}^{3}\right), C_{2}$ is the concentration of the $\mathrm{NaOH}$ solution $(0.052 \mathrm{M}), V_{2}$ is the volume of the $\mathrm{NaOH}$ solution used for the titration, and $m$ is the mass of the copolymer sample.

\subsection{Sorption experiments}

The effect of $\mathrm{pH}$ on the sorption capacity of 10MAG-SGE60-deta was investigated in mixed $\mathrm{Mo}(\mathrm{VI})\left(C_{i}=0.01 \mathrm{M}\right)$ and $\operatorname{Re}(\mathrm{VII})$ $\left(C_{i}=0.005 \mathrm{M}\right)$ aqueous solutions in batch static experiments, in the $\mathrm{pH}$ range $1-8$, at room temperature $(298 \mathrm{~K})$. The same volume of the mixed $\mathrm{Mo}(\mathrm{VI}) / \operatorname{Re}(\mathrm{VII})$ solution $\left(V=10.0 \mathrm{~cm}^{3}\right)$ and copolymer mass of $0.1 \mathrm{~g}$ was used in all the experiments. The desired $\mathrm{pH}$ was adjusted by adding the appropriate amounts of $1 \mathrm{M} \mathrm{HCl}$ and $1 \mathrm{M}$ $\mathrm{NaOH}, \mathrm{pH}$ values were monitored with the $\mathrm{pH}-$ meter. Metal analysis of the aliquots withdrawn at $3 \mathrm{~h}$ and $24 \mathrm{~h}$ was carried with ICPOES.

The effect of initial concentration of $\mathrm{Mo}(\mathrm{VI})$ ions $\left(C_{i}=0.01,0.02\right.$, 0.05 and $0.1 \mathrm{M})$ at constant initial concentration of $\operatorname{Re}(\mathrm{VII})$ ions $\left(C_{i}=0.005 \mathrm{M}\right)$ on the sorption capacity of 10MAG-SGE60-deta from mixed $\mathrm{Mo}(\mathrm{VI}) / \operatorname{Re}(\mathrm{VII})$ solutions was investigated after $180 \mathrm{~min}$ at $\mathrm{pH}=4$ and $298 \mathrm{~K}$. The same volume of the mixed $\mathrm{Mo}(\mathrm{VI}) / \operatorname{Re}(\mathrm{VII})$ solution $\left(\mathrm{V}=5.0 \mathrm{~cm}^{3}\right)$ and copolymer mass of $0.05 \mathrm{~g}$ was used in all the experiments.

In order to investigate the sorption efficiency of 10MAG-SGE60deta for $\mathrm{Mo}(\mathrm{VI})$ and $\operatorname{Re}(\mathrm{VII})$ in the presence of various coexisting cations, $0.1 \mathrm{~g}$ of 10MAG-SGE60-deta was contacted with $10 \mathrm{~cm}^{3}$ of mixed solution $\left(5 \mathrm{~cm}^{3}\right.$ of $\mathrm{NiCl}_{2} \cdot 6 \mathrm{H}_{2} \mathrm{O}, \mathrm{CdCl}_{2}$ or $\mathrm{CuCl}_{2} \cdot 2 \mathrm{H}_{2} \mathrm{O}$ and $5 \mathrm{~cm}^{3}$ of $\mathrm{Mo}(\mathrm{VI})$ or $\mathrm{Re}(\mathrm{VII})$ single solution). The initial concentration of $\mathrm{Mo}(\mathrm{VI})$ and $\mathrm{Re}(\mathrm{VII})$ solutions were $0.01 \mathrm{M}$ and $0.005 \mathrm{M}$, respectively. The ratio of metal to cation concentrations was 2:1 and 4:1. The experiments were performed in batch static experiments, at $\mathrm{pH}=4$, and room temperature ( $298 \mathrm{~K}$ ). After $3 \mathrm{~h}$, the mixture was filtered and the $\mathrm{Mo}(\mathrm{VI})$ and $\mathrm{Re}(\mathrm{VII})$ concentrations in the supernatant were analyzed with ICP-OES.

To investigate the sorption efficiency of 10MAG-SGE60-deta for $\mathrm{Mo}(\mathrm{VI})$ and $\operatorname{Re}(\mathrm{VII})$ in the presence of various coexisting anions, $0.1 \mathrm{~g}$ of 10MAG-SGE60-deta was contacted with $10 \mathrm{~cm}^{3}$ of mixed solution $\left(5 \mathrm{~cm}^{3}\right.$ of $\mathrm{NaCl}, \mathrm{NaNO}_{3}$ or $\mathrm{Na}_{2} \mathrm{SO}_{4}$ and $5 \mathrm{~cm}^{3}$ of $\mathrm{Mo}(\mathrm{VI})$ or $\mathrm{Re}(\mathrm{VII})$ solution). The initial concentration of $\mathrm{Mo}(\mathrm{VI})$ and $\mathrm{Re}(\mathrm{VII})$ solutions were $0.01 \mathrm{M}$ and $0.005 \mathrm{M}$, respectively. The anions concentration was in the range $0.01-0.04 \mathrm{M}$. The ratio of metal to anions concentration was $1: 2$ and 1:4. The experiments were performed in batch static experiments, at $\mathrm{pH}=4$, and room temperature $(298 \mathrm{~K})$. After $3 \mathrm{~h}$, the mixture was filtered and the $\mathrm{Mo}(\mathrm{VI})$ and $\operatorname{Re}(\mathrm{VII})$ concentrations in the supernatant were analyzed with ICP-OES.

For investigations of the solution ionic strength, $0.1 \mathrm{~g}$ of 10MAG-SGE60-deta was contacted with $10 \mathrm{~cm}^{3}$ of mixed solution ( $5 \mathrm{~cm}^{3}$ of $\mathrm{NaCl}$ and $5 \mathrm{~cm}^{3}$ of $\mathrm{Mo}(\mathrm{VI})$ or $\mathrm{Re}(\mathrm{VII})$ single solution). The initial concentration of $\mathrm{Mo}(\mathrm{VI})$ and $\operatorname{Re}(\mathrm{VII})$ solutions were $0.01 \mathrm{M}$ and $0.005 \mathrm{M}$, respectively. The $\mathrm{NaCl}$ concentration was in the range $0.005-0.01 \mathrm{M}$. The ratio of metal to $\mathrm{NaCl}$ concentration was $1: 1,1: 5$ and $1: 10$. The experiments were performed in batch static experiments, at $\mathrm{pH}=4$ and room temperature $(298 \mathrm{~K})$. After $3 \mathrm{~h}$, the mixture was filtered and the $\mathrm{Mo}(\mathrm{VI})$ and $\operatorname{Re}(\mathrm{VII})$ concentrations in the supernatant were analyzed with ICP-OES.

In the adsorption isotherm experiments, $0.1 \mathrm{~g}$ of 10MAG-SGE60deta was contacted with $10 \mathrm{~cm}^{3}$ of $\mathrm{Mo}(\mathrm{VI})\left(C_{i}=0.002 ; 0.005 ; 0.01\right.$ and $0.02 \mathrm{M})$ and $\operatorname{Re}(\mathrm{VII})\left(C_{i}=0.001 ; 0.002 ; 0.005\right.$ and $\left.0.01 \mathrm{M}\right)$ single solutions, at $\mathrm{pH}=4$ and $\mathrm{T}=298 \mathrm{~K}$, for $24 \mathrm{~h}$.

In order to estimate the amount of leachable magnetite from the 10MAG-SGE60-deta, $0.1 \mathrm{~g}$ of copolymer particles, was contacted with $10 \mathrm{~mL}$ of deionized water at $\mathrm{pH} 2$ and 4 for $24 \mathrm{~h}$. The amount of leached magnetite was determined by ICP-OES. The experiments showed that there was no measurable magnetite release.

Standard statistical methods were used to determine the mean values and standard deviations for each set of data. Each experiment was repeated three times or more if necessary. Relative standard deviations did not exceed 5.0\%.

The amount of $\mathrm{Mo}(\mathrm{VI})$ and $\operatorname{Re}(\mathrm{VII})$ sorbed at any time $t$, per unit mass of the sorbent beads $(m, g)$ was calculated as the difference between the initial and final concentration by the equation:

$Q_{t}=\frac{\left(C_{i}-C_{t}\right) V}{m}$

where: $Q_{t}$ is sorption capacity $\left(\mathrm{mmol} \mathrm{g}^{-1}\right), C_{i}$ and $C_{t}$ are concentrations of $\mathrm{Mo}(\mathrm{VI})$ ions in the initial solution and in aqueous solution at time $t(\mathrm{~min}), V$ is the volume of the aqueous phase $\left(\mathrm{dm}^{3}\right)$.

Distribution factor $(D)$ and separating factor $\left(\beta_{R e / M o}\right)$ were calculated from Equations (3) and (4) [8]:

$\mathrm{D}=\frac{\mathrm{Q}_{\mathrm{t}}}{\mathrm{C}_{\mathrm{e}}}$

$\beta_{\mathrm{Re} / \mathrm{Mo}}=\frac{\mathrm{D}_{\mathrm{Re}}}{\mathrm{D}_{\mathrm{Mo}}}$

where $C_{e}$ is equilibrium concentrations of $\mathrm{Mo}(\mathrm{VI})$ and $\operatorname{Re}(\mathrm{VII})$ ions.

\section{Results and discussion}

\subsection{Characterization of mPGME samples}

The obtained magnetic copolymer samples were sieved with $0.15,0.30$ and $0.63 \mathrm{~mm}$ sieves. The results of sieve analysis are presented in Fig. 1.

As can be seen, the particle fraction with diameter in $0.15-0.30 \mathrm{~mm}$ range is highly dominant, with 70 mass\% and 75 mass\% for the samples with 2 and $10 \%$ of magnetite, respectively.

The elemental analysis of the samples 10MAG-SGE60 and 10MAG-SGE60-deta is presented in Table 1. The amino group concentration $\left(C_{A G}\right)$ of 10MAG-SGE60-deta calculated from the elemental analysis was $4.21 \mathrm{mmol} \mathrm{g}^{-1}$, while the value obtained by titration was $3.56 \mathrm{mmol} \mathrm{g}^{-1}$. This difference can be ascribed to the fact that some epoxy groups (and amino groups after 


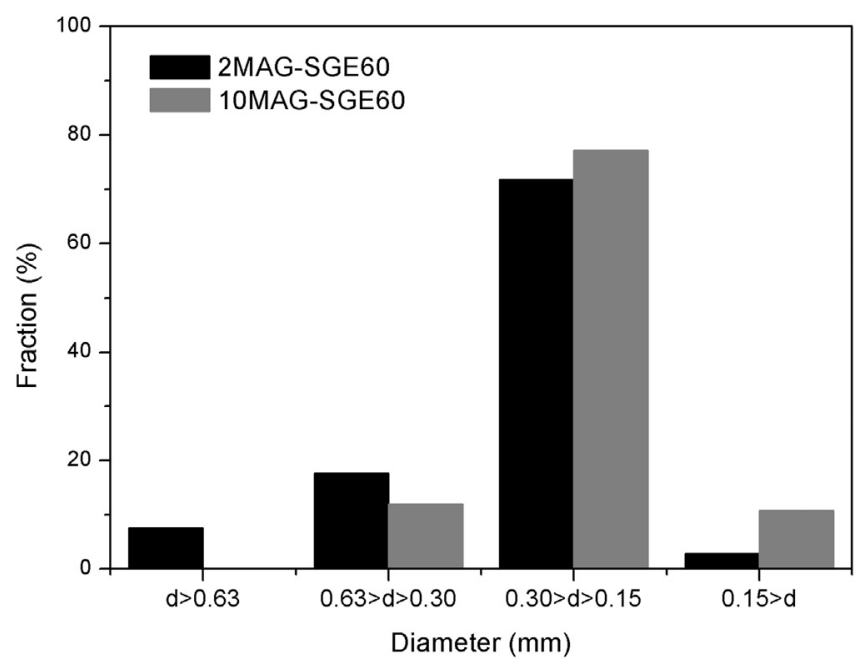

Fig. 1. Sieve analysis of mPGME samples.

Table 1

Elemental analysis of 10MAG-SGE60 and 10MAG-SGE60-deta.

\begin{tabular}{llll}
\hline Sample & Found & \\
\cline { 2 - 4 } & $\% \mathrm{C}$ & $\% \mathrm{H}$ & $\% \mathrm{~N}$ \\
\hline 10MAG-SGE60 & $51.4 \pm 0.103$ & $6.1 \pm 0.012$ & - \\
10MAG-SGE60-deta & $50.9 \pm 0.102$ & $7.4 \pm 0.015$ & $5.9 \pm 0.012$ \\
\hline
\end{tabular}

functionalization) remain trapped inside the copolymer particle, being not accessible for titration [27].

The cumulative pore volume distribution curves for selected samples are presented in Fig. 2. The porosity parameters (specific pore volume, $V_{S}$, specific surface area, $S_{H g}$, and pore diameter that corresponds to half of the pore volume, $D_{V / 2}$ ) of the mPGME and mPGME-deta samples were calculated from the cumulative pore volume distribution curves as described in the literature [22] and presented Table 2.

The increase of magnetite content in the reaction mixture from 2 to 10 mass\% caused a shift in the pore size distribution curves of the synthesized samples towards smaller pores, which consequently led to the increase of $S_{\mathrm{Hg}}$ (for 1.6 times) and the decrease of

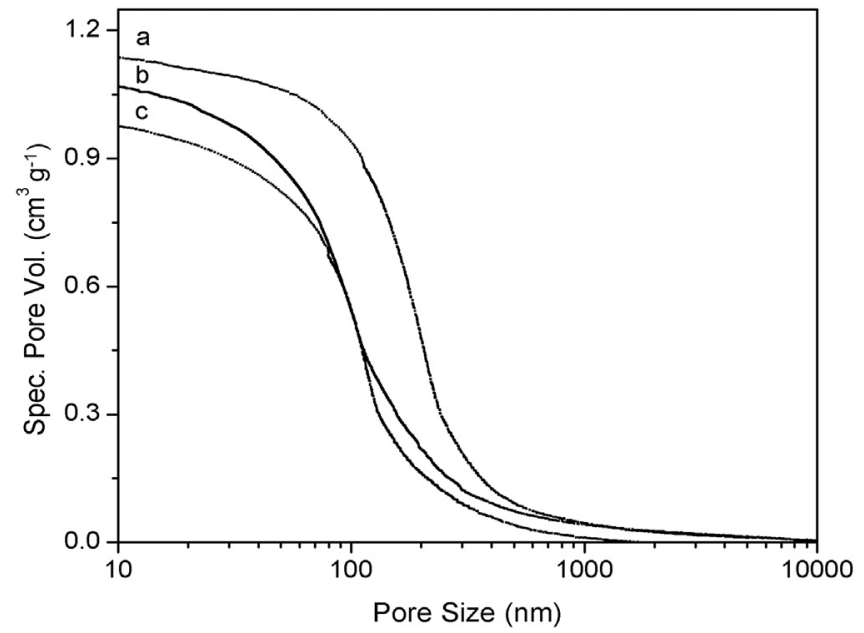

Fig. 2. Cumulative pore volume distribution curves for (a) 2MAG-SGE60, (b) 10MAGSGE60 and (c) 10MAG-SGE60-deta.
Table 2

Porosity parameters of 2MAG-SGE60, 10MAG-SGE60 and 10MAG-SGE60-deta

\begin{tabular}{llll}
\hline Sample & $\mathrm{V}_{\mathrm{s}}, \mathrm{cm}^{3} \mathrm{~g}^{-1}$ & $\mathrm{~S}_{\mathrm{s}}, \mathrm{m}^{2} \mathrm{~g}^{-1}$ & $\mathrm{D}_{\mathrm{V} / 2}, \mathrm{~nm}$ \\
\hline 2MAG-SGE60 & 1.14 & 42 & 182 \\
10MAG-SGE60 & 1.08 & 67 & 100 \\
10MAG SGE60-deta & 0.99 & 59 & 104 \\
\hline
\end{tabular}

$D_{V / 2}$ (for 1.8 times). However, the influence of aminofunctionalization on the porosity parameters was not so significant.

In order to confirm the presence of magnetite on the outer and inner surface of hybrid PGMA microspheres, the FTIR spectra of 2MAG-SGE60, 10MAG-SGE60 and 10MAG-SGE60-deta were recorded and presented in Fig. 3.

In the FTIR spectra of magnetic copolymer samples the characteristic absorption bands at $2990 \mathrm{~cm}^{-1}, 2950 \mathrm{~cm}^{-1}$ and $2830 \mathrm{~cm}^{-1}$ [methyl and methylene stretching vibrations, $v(\mathrm{C}-\mathrm{H})$ ], $\sim 1730 \mathrm{~cm}^{-1}$ $[v(\mathrm{C}=\mathrm{O})], \sim 1390$ and $1460 \mathrm{~cm}^{-1}\left[\delta(\mathrm{C}-\mathrm{H})_{\text {asym }}\right.$ and $\left.\delta(\mathrm{C}-\mathrm{H})_{\text {sym }}\right]$ and $1150 \mathrm{~cm}^{-1}[v(\mathrm{C}-\mathrm{O}-\mathrm{C})]$ were observed. Also, the epoxy peaks were found in the 2MAG-SGE60 and 10MAG-SGE60 spectrum at $~ 850$ and $\sim 910 \mathrm{~cm}^{-1}$ (epoxy ring vibrations) and $\sim 1260 \mathrm{~cm}^{-1}[\delta(\mathrm{C}-\mathrm{H})$ epoxy].

The characteristic stretching frequencies of the aminofunctionalized sample 10MAG-SGE60-deta appeared at 3700$3050 \mathrm{~cm}^{-1}[v(\mathrm{~N}-\mathrm{H})+v(\mathrm{O}-\mathrm{H})], 1582 \mathrm{~cm}^{-1}[\delta(\mathrm{NH})]$ and $1655 \mathrm{~cm}^{-1}$ $\left[\delta\left(\mathrm{NH}_{2}\right)\right]$. The characteristic peak at $\sim 590 \mathrm{~cm}^{-1}$ that originates from $\mathrm{Fe}-\mathrm{O}$ vibrations in magnetite [28] present in the spectra of 2MAGSGE60 (weak peak), 10MAG-SGE60 and 10MAG-SGE60-deta confirms the incorporation of magnetite nanoparticles onto the mPGME microspheres.

The morphology of particle surface and cross-section for selected magnetic samples was examined by SEM analysis (Fig. 4 and Fig. 5.). For further analysis, the energy-dispersive X-ray spectroscopy (SEM-EDS) was performed on both surface and crosssection of 2MAG-SGE60, 10MAG-SGE60 and 10MAG-SGE60-deta particles. The results were presented in Fig. 4 and Table 3.

These micrographs clearly demonstrate three dimensional porous structure of the samples, composed of a large number of globules and interconnected with channels and pores. Highly developed internal porous structure decreases the mass transfer resistance, facilitates the diffusion of metal ions and consequently provides high adsorption rate and capacity [29]. The SEM-EDS analysis confirmed the presence of all expected elements $(C, O, N$ and $\mathrm{Fe}$ ). As can be seen, the $\mathrm{N}$ percentage was higher on the particles surface then in the cross-section indicating that the reaction of epoxy groups with diethylene triamine occurs predominantly on the particle surface.

Surface characterization with scanning electron microscopy indicates that, although predominantly present at the particle surface, the iron nanoparticles were also embedded in the bulk to a certain extent.

Fig. 6 shows the TEM micrographs of magnetic 2MAG-SGE60 and 10MAG-SGE60 samples.

The TEM images show a distribution of dark magnetic nanoparticles throughout the gray copolymer matrix. Similar was reported for magnetic nanocomposite based on functionalized crosslinked poly(methylacrylate) [30] and magnetic porous poly(MMAco-DVB) microspheres [31].

The magnetization measurements of mPGME samples having $2 \%$ and $10 \%$ mass content of magnetite nanoparticles were performed at room temperature $(300 \mathrm{~K})$ on a SQUID-based magnetometer in the \pm 5 T field range. The so recorded $M-H$ curves for samples 2MAG-SGE60 and 10MAG-SGE60 are presented in Fig. 7. 


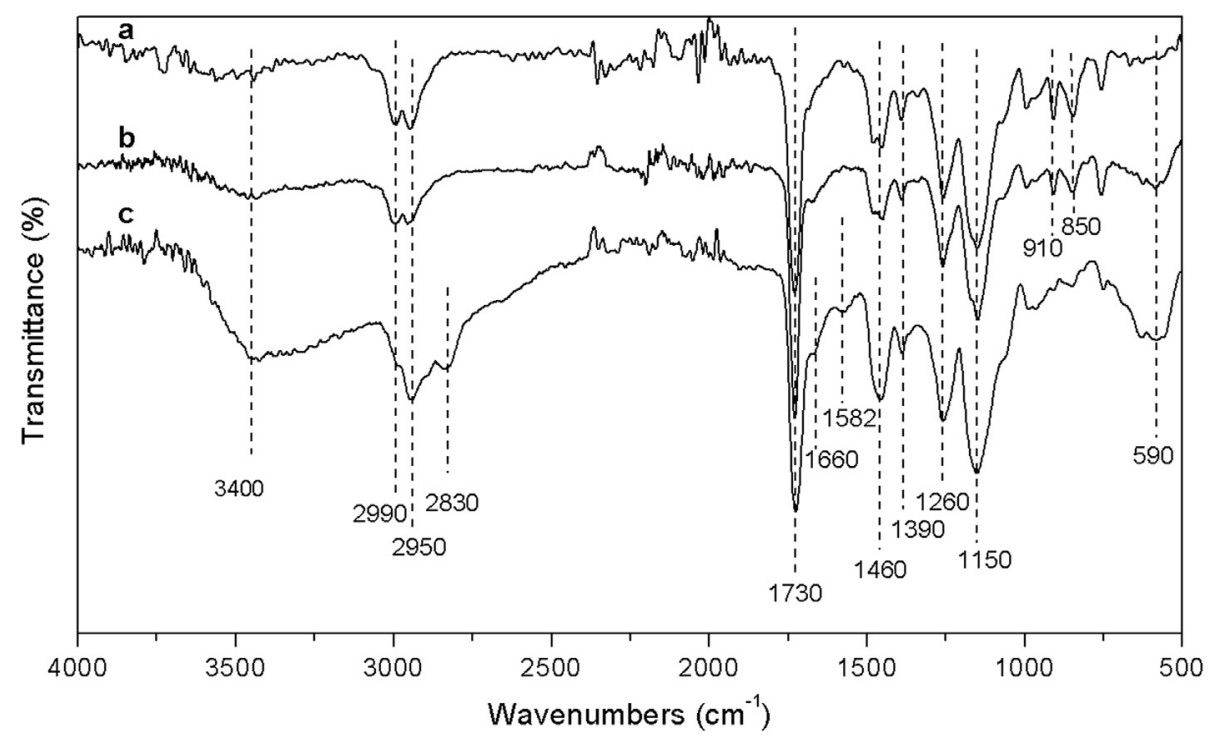

Fig. 3. FTIR spectra of (a) 2MAG-SGE60, (b) 10MAG-SGE60 and (c) 10MAG-SGE60-deta.

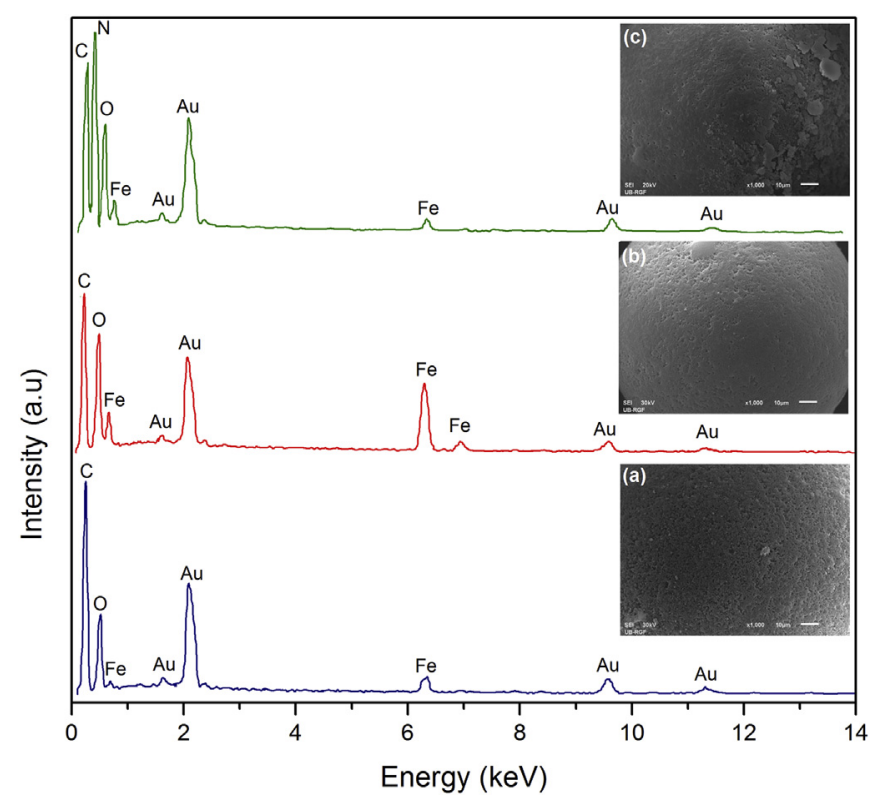

Fig. 4. SEM microphotographs of particle surface and SEM/EDS spectra for (a) 2MAGSGE60, (b) 10MAG SGE-60 and (c) 10MAG-SGE60-deta (magnification 5000×).
Both mPGME samples showed superparamagnetic behavior with negligible hysteresis loop. Magnetization curves showed an expected increase in the magnetization value with increasing magnetite content. The obtained values of saturation magnetization (1.2 and $5.8 \mathrm{emu} \mathrm{g}^{-1}$ for samples 2MAG-SGE60 and 10MAGSGE60, respectively) and their ratio close to $1: 5$ showed that nominal magnetite content has been achieved in the synthesized composites. This ratio also points to the fact that magnetite nanoparticles do not agglomerate within MPGME particles thus preserving favorable superparamagnetic behavior.

\subsection{Molybdenum (VI) and rhenium (VII) sorption on mPGME-deta}

It is generally known that initial $\mathrm{pH}$ of the sorbate/sorbent system is a critical process parameter because the aqueous chemistry and the surface binding sites of the sorbent are dependent on the $\mathrm{pH}$ value of the mixture. In aqueous solution, perrhenate species $\left(\mathrm{ReO}_{4}^{-}\right)$shows stability in $\mathrm{pH}$ range $1-10$, however, the structure of $\mathrm{Mo}(\mathrm{VI})$ strongly depends on $\mathrm{pH}$ values and the total metal concentration [9]. In pH range $\mathrm{pH} 2-6$, heptamolybdate anion $\mathrm{Mo}_{7} \mathrm{O}_{24}^{6-}$ predominates in aqueous solutions [32]. This polyanion can be protonated at low $\mathrm{pH}$ values forming polynuclear hydrolyzed species such as $\mathrm{Mo}_{7} \mathrm{O}_{21}(\mathrm{OH})_{3}^{3-}$, $\mathrm{Mo}_{7} \mathrm{O}_{22}(\mathrm{OH})_{2}^{4-}$ and $\mathrm{Mo}_{7} \mathrm{O}_{23}(\mathrm{OH})^{5-}$. In alkaline and neutral aqueous solutions, molybdenum oxyanions exist in the form of
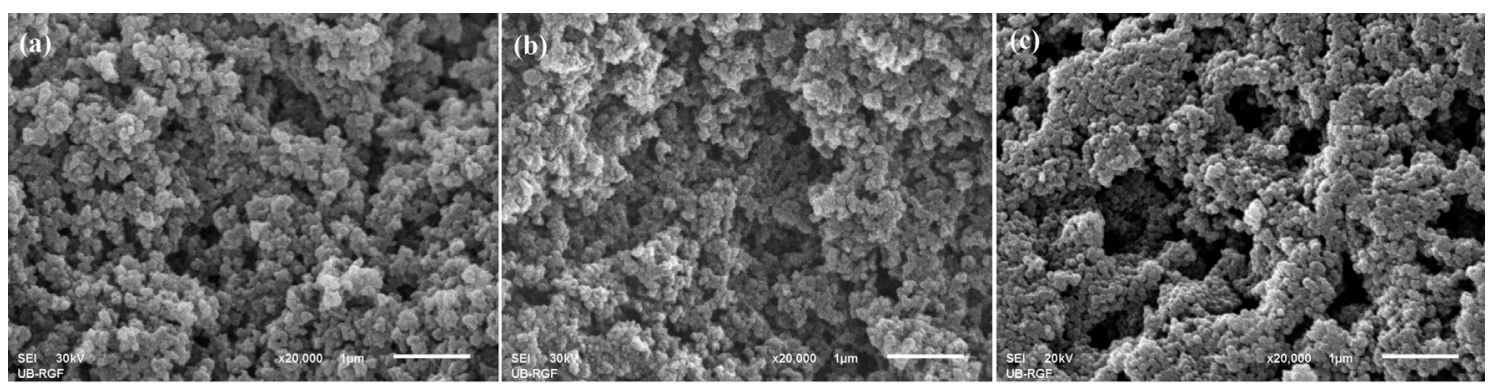

Fig. 5. SEM microphotographs of particle cross-section for 2MAG-SGE60 (a), 10MAG SGE-60 (b) and 10MAG-SGE60-deta (c) (magnification 20000×). 
Table 3

Results of SEM-EDS analysis of 2MAG-SGE60, 10MAG-SGE60 and 10MAG-SGE60-deta particle surface and cross-section.

\begin{tabular}{|c|c|c|c|c|c|c|c|c|c|c|c|c|}
\hline \multirow[t]{3}{*}{ Element } & \multicolumn{4}{|c|}{ 2MAG-SGE60 } & \multicolumn{4}{|c|}{ 10MAG-SGE60 } & \multicolumn{4}{|c|}{ 10MAG-SGE60-deta } \\
\hline & \multicolumn{2}{|c|}{ Particle surface } & \multicolumn{2}{|c|}{ Cross-section } & \multicolumn{2}{|c|}{ Particle surface } & \multicolumn{2}{|c|}{ Cross-section } & \multicolumn{2}{|c|}{ Particle surface } & \multicolumn{2}{|c|}{ Cross-section } \\
\hline & Weight \% & Atomic \% & Weight \% & Atomic \% & Weight \% & Atomic \% & Weight \% & Atomic \% & Weight \% & Atomic \% & Weight \% & Atomic \% \\
\hline $\mathrm{C}-\mathrm{K}$ & 60.1 & 67.9 & 63.9 & 69.6 & 45.5 & 57.9 & 70.3 & 77.0 & 61.2 & 67.7 & 75.6 & 80.4 \\
\hline $\mathrm{O}-\mathrm{K}$ & 37.0 & 31.4 & 36.6 & 30.3 & 38.0 & 37.1 & 27.3 & 22.4 & 21.4 & 17.8 & 14.9 & 11.9 \\
\hline $\mathrm{N}-\mathrm{K}$ & - & - & - & - & - & - & - & - & 14.5 & 13.7 & 8.1 & 7.4 \\
\hline $\mathrm{Fe}-\mathrm{K}$ & 2.9 & 0.71 & 0.49 & 0.12 & 16.5 & 5.0 & 2.4 & 0.61 & 2.9 & 0.70 & 1.5 & 0.39 \\
\hline
\end{tabular}

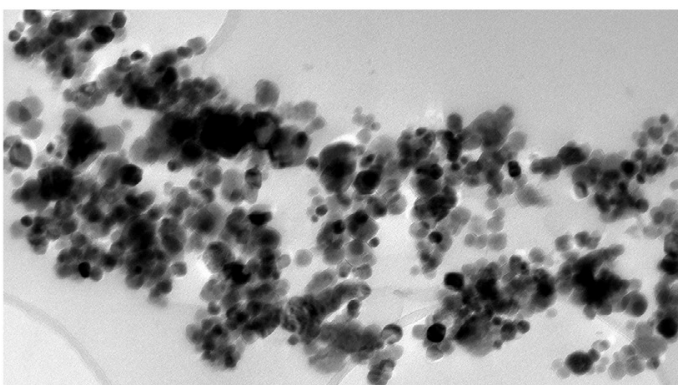

(a)

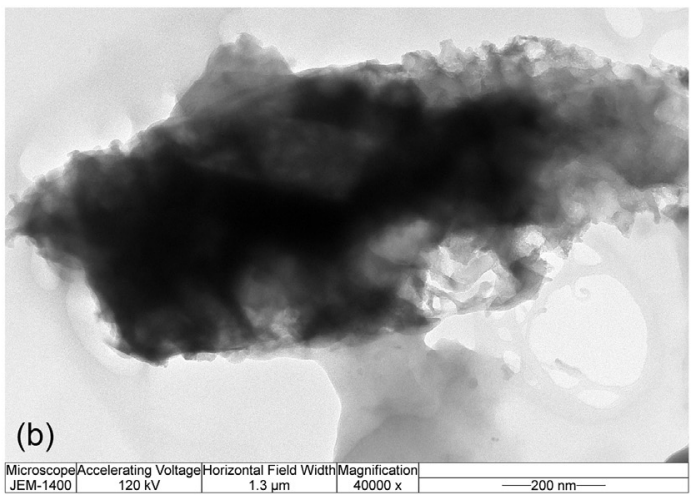

(b)

Fig. 6. TEM images of magnetic samples: (a) 2MAG-SGE60 and (b) 10MAG-SGE60

monomeric $\left[\mathrm{MoO}_{4}\right]^{2-}$ ion.

The functional groups and $\mathrm{pH}$ PzC of the sorbent surface are important because they indicate the acidity/basicity of the sorbent, i.e. the surface charge of the sorbent, which in turn is influenced by the solution $\mathrm{pH}$. To determine the $\mathrm{pH}_{\mathrm{PZC}}$ of the initial and aminofunctionalized magnetic copolymer samples 10MAG-SGE60 and 10MAG-SGE60-deta the $\mathrm{pH}$ drift method was used and the experimental results are shown in Fig. 8.

The $\mathrm{pH}_{\mathrm{PZC}}$ is the point where the curve of $\mathrm{pH}_{\mathrm{f}} \mathrm{vs} . \mathrm{pH}_{\mathrm{i}}$ intersects the line $\mathrm{pH}_{\mathrm{i}}=\mathrm{pH}_{\mathrm{f}}$. The $\mathrm{pHPZC}$ values of 10MAG-SGE60 and 10MAGSGE60-deta determined by the $\mathrm{pH}$ drift method were 6.0 and 7.2, respectively. As already observed, when the solution $\mathrm{pH}$ was lower than $\mathrm{pH}_{\mathrm{PZC}}$, the removal of oxyanions was relatively high, possibly

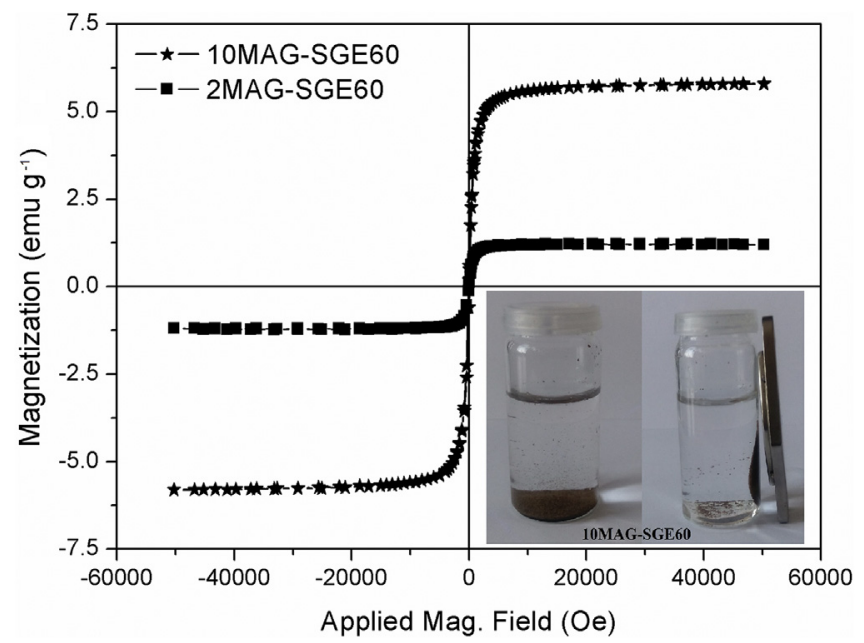

Fig. 7. Magnetic hysteresis curves of $2 M A G-S G E 60$ and 10MAG-SGE60 recorded at $300 \mathrm{~K}$. Inset: 10MAG-SGE60 precipitate completely attracted by the external permanent magnet. due to the presence of more positive charges on the PGME-deta surface [33]. Namely, at acidic pH values, the attraction between the protonated amino groups of mPGME-deta and the Mo(VI) and $\operatorname{Re}(\mathrm{VII})$ oxyanions could be expected. In contrast, negatively charged sorbent surface sites do not promote the anions sorption, due to the electrostatic repulsion. Also, the pKa value of amine groups typically lies within the range 8-10 [34], implying that the amine groups are fully protonated at $\mathrm{pH}<5$ and that the extent of protonation slowly decreases with the increase in $\mathrm{pH}$

The effect of $\mathrm{pH}$ on the $\mathrm{Re}(\mathrm{VII})$ and $\mathrm{Mo}(\mathrm{VI})$ sorption from mixed solutions was investigated by varying $\mathrm{pH}$ in the range 1-8 and the results were presented in Fig. 9.

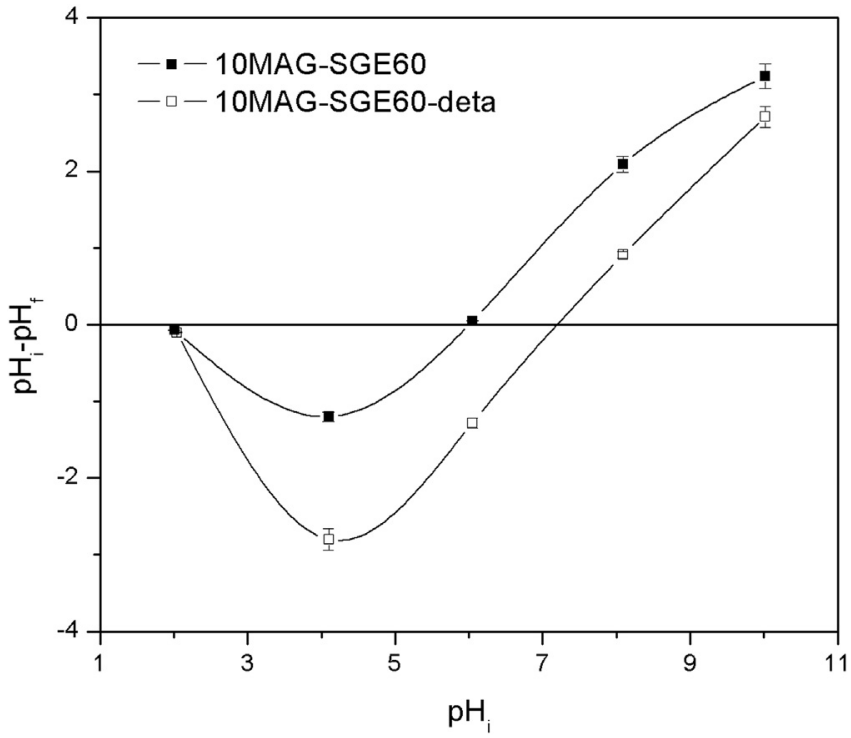

Fig. 8. Point of zero charge (pHpzc) of 10MAG-SGE60 and 10MAG-SGE60-deta determined by the $\mathrm{pH}$ drift method. Standard errors are shown as vertical error bars. 

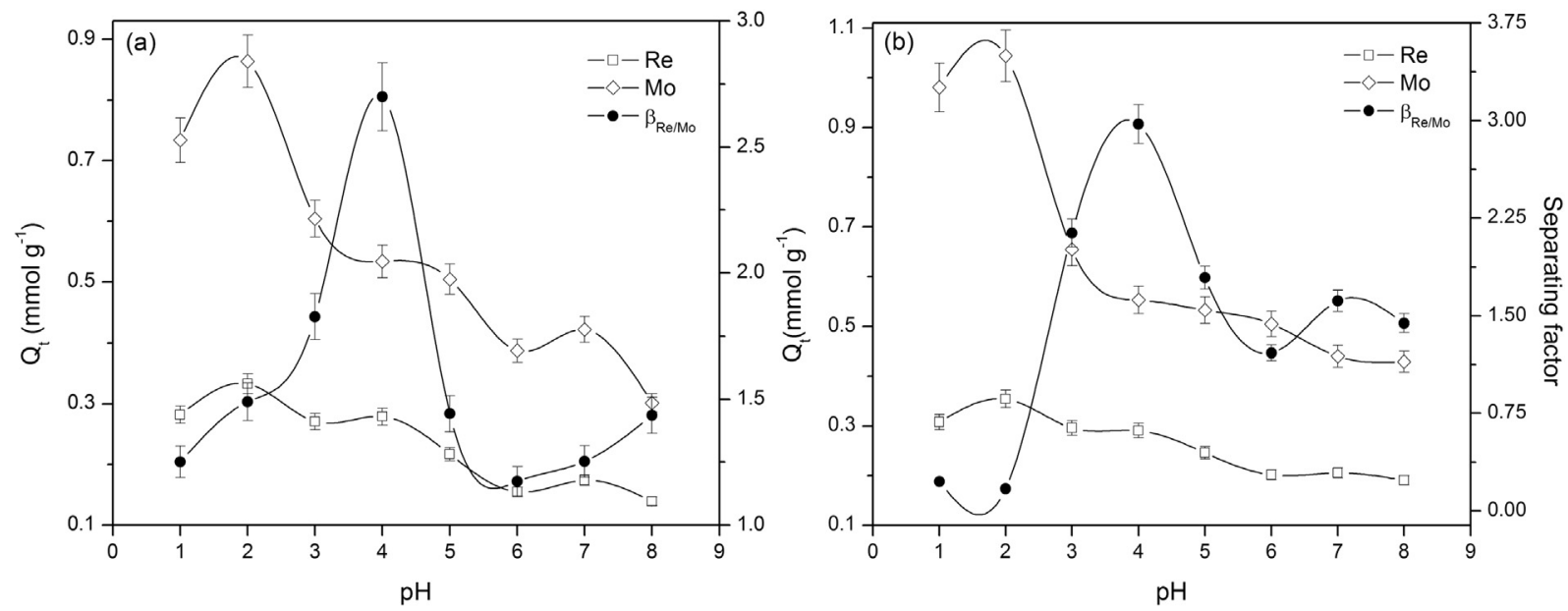

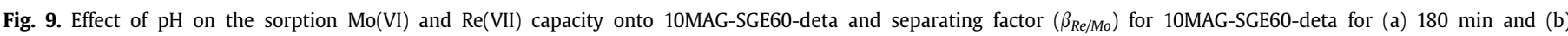
$24 \mathrm{~h}\left(T=298 \mathrm{~K}, \mathrm{Mo}(\mathrm{VI}): C_{i}=0,01 \mathrm{M}\right.$ and $\left.\mathrm{Re}(\mathrm{VII}): C_{i}=0.005 \mathrm{M}\right)$. Standard errors are shown as vertical error bars.

As seen from Fig. 9 the similar sorption profiles were obtained for both sorption times, $180 \mathrm{~min}$ and $24 \mathrm{~h}$. The maximum $\mathrm{Mo}(\mathrm{VI})$ and $\mathrm{Re}(\mathrm{VII})$ sorption capacities were attained at $\mathrm{pH} 2.0$ and declined with further $\mathrm{pH}$ increase. Due to the fact that the separating factor $\left(\beta_{R e / M o}\right)$ reached its maximum at $\mathrm{pH} 4.0$, all further tests were conducted at this $\mathrm{pH}$ value.

In order to study the selectivity of 10MAG-SGE60-deta for $\operatorname{Re}(\mathrm{VII})$ sorption from the $\mathrm{Mo}(\mathrm{VI}) / \operatorname{Re}(\mathrm{VII})$ mixed solutions, the experiments with different Re:Mo molar ratio (1:2,1:4,1:10 and 1:20) were performed. Also, the effect of time for $\mathrm{pH} 2.0,4.0$ and 6.0 value on the sorbent selectivity was studied for Re:Mo molar ratio (1:2) and the results were presented in Table 4 . The selectivity for $\operatorname{Re}(\mathrm{VII})$ sorption was expressed through the separation factor, $\beta_{R e / M o}$.

The selectivity for $\operatorname{Re}(\mathrm{VII})$ sorption expressed through $\beta_{R e / M o}$ shows increase with the increase of initial $\mathrm{Mo}(\mathrm{VI})$ concentration and reaches the maximum at Re:Mo $=1: 20$. At the lowest Re:Mo ratio (1:2) $\beta_{\text {Re/Mo }}$ shows undesired variations within contact time of $30 \mathrm{~min}$, time too short for equilibrium sorption. According to obtained results 180 min would be sufficient to attain equilibrium which is considered as adequate and economical for wastewater treatment [35].

\subsection{Effect of coexisting background cations and anions}

The effect of coexisting background anions and cations on $\mathrm{Mo}(\mathrm{VI})$ and $\mathrm{Re}(\mathrm{VII})$ sorption capacity examined by using three anions $\left(\mathrm{Cl}^{-}, \mathrm{NO}_{3}^{-}\right.$and $\left.\mathrm{SO}_{4}^{2-}\right)$ and three divalent $\left(\mathrm{Ni}^{2+}, \mathrm{Cd}^{2+}\right.$ and $\left.\mathrm{Cu}^{2+}\right)$ cations are presented in Fig. 10 and Fig. 11. The alkali and alkaline

Table 4

Selective sorption of $\operatorname{Re}(\mathrm{VII})$ and $\mathrm{Mo}(\mathrm{VI})$ from mixed solutions $(\mathrm{pH}=4.0,298 \mathrm{~K}$ $\mathrm{Mo}(\mathrm{VI}): C_{i}=0.01,0.02,0.05$ and $\left.0.1 \mathrm{M}, \operatorname{Re}(\mathrm{VII}): C_{i}=0.005 \mathrm{M}\right)$.

\begin{tabular}{|c|c|c|c|c|}
\hline & & & & $\beta_{R e / M o}$ \\
\hline \multirow{6}{*}{$\mathrm{pH}=4$} & & Re:Mo = 1:2 & & 2.6 \\
\hline & & Re:Mo = 1:4 & & 1.7 \\
\hline & & Re:Mo = 1:10 & & 3.8 \\
\hline & & Re:Mo = 1:20 & & 8.4 \\
\hline & & \multicolumn{3}{|l|}{$\beta_{R e / M o}$} \\
\hline & & $\mathrm{pH}=2$ & $\mathrm{pH}=4$ & $\mathrm{pH}=6$ \\
\hline \multirow{3}{*}{ Re:Mo $=1: 2$} & $5 \mathrm{~min}$ & 1.9 & 0.8 & 3.3 \\
\hline & $15 \mathrm{~min}$ & 1.6 & 0.7 & 4.0 \\
\hline & $30 \mathrm{~min}$ & 1.7 & 1.9 & 2.8 \\
\hline
\end{tabular}
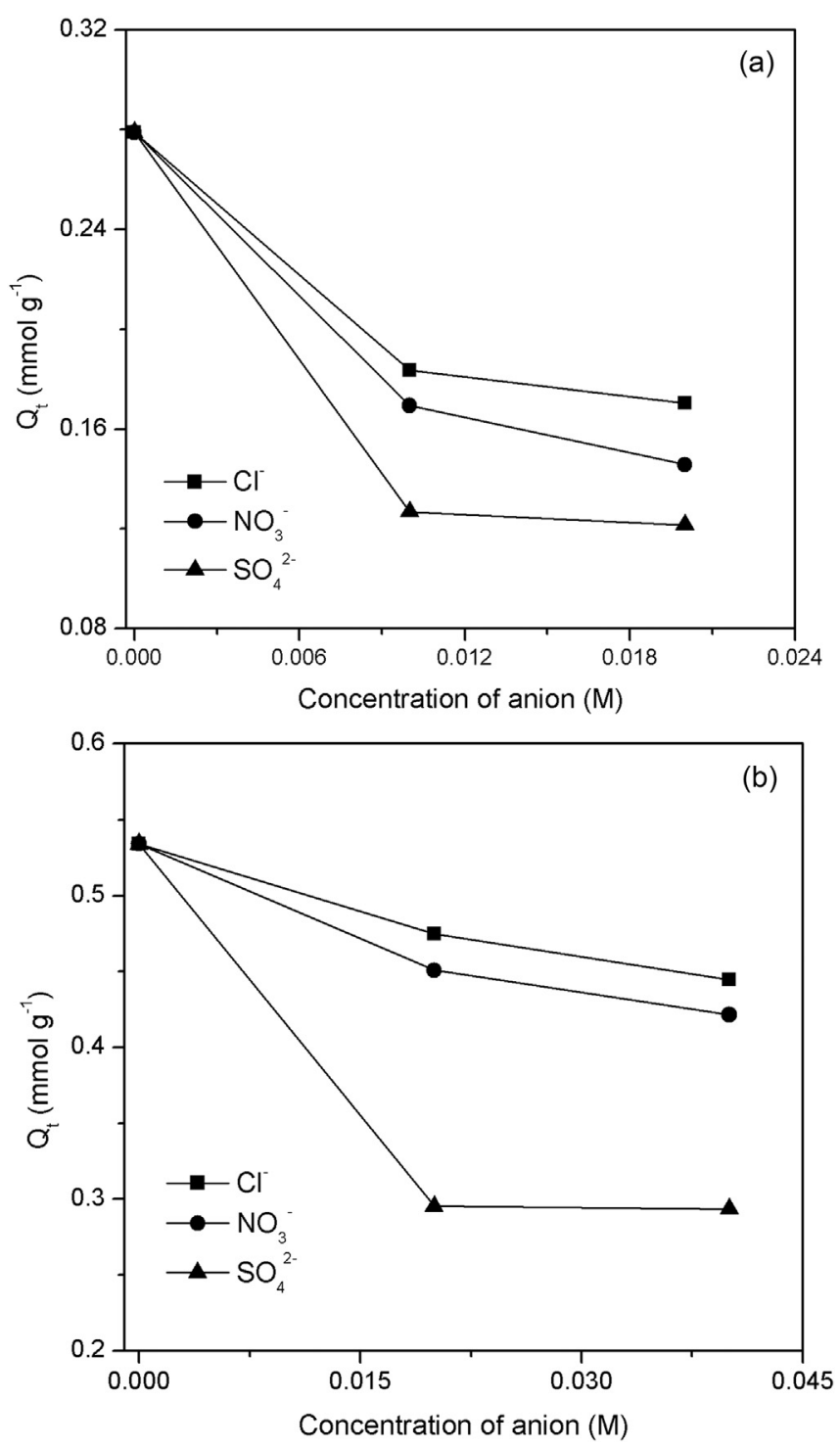

Fig. 10. Effects of background anions on $\operatorname{Re}(\mathrm{VII})$ (a) and $\mathrm{Mo}(\mathrm{VI})$ (b) sorption onto 10MAG-SGE60-deta (metal to anions concentration ratio $1: 2$ and $1: 4, C_{i}=0.01 \mathrm{M}$ for $\mathrm{Mo}(\mathrm{VI}), C_{i}=0.005 \mathrm{M}$ for $\operatorname{Re}(\mathrm{VII}), \mathrm{pH}=4, \mathrm{~T}=298 \mathrm{~K}, \mathrm{t}=3 \mathrm{~h}$ ). 

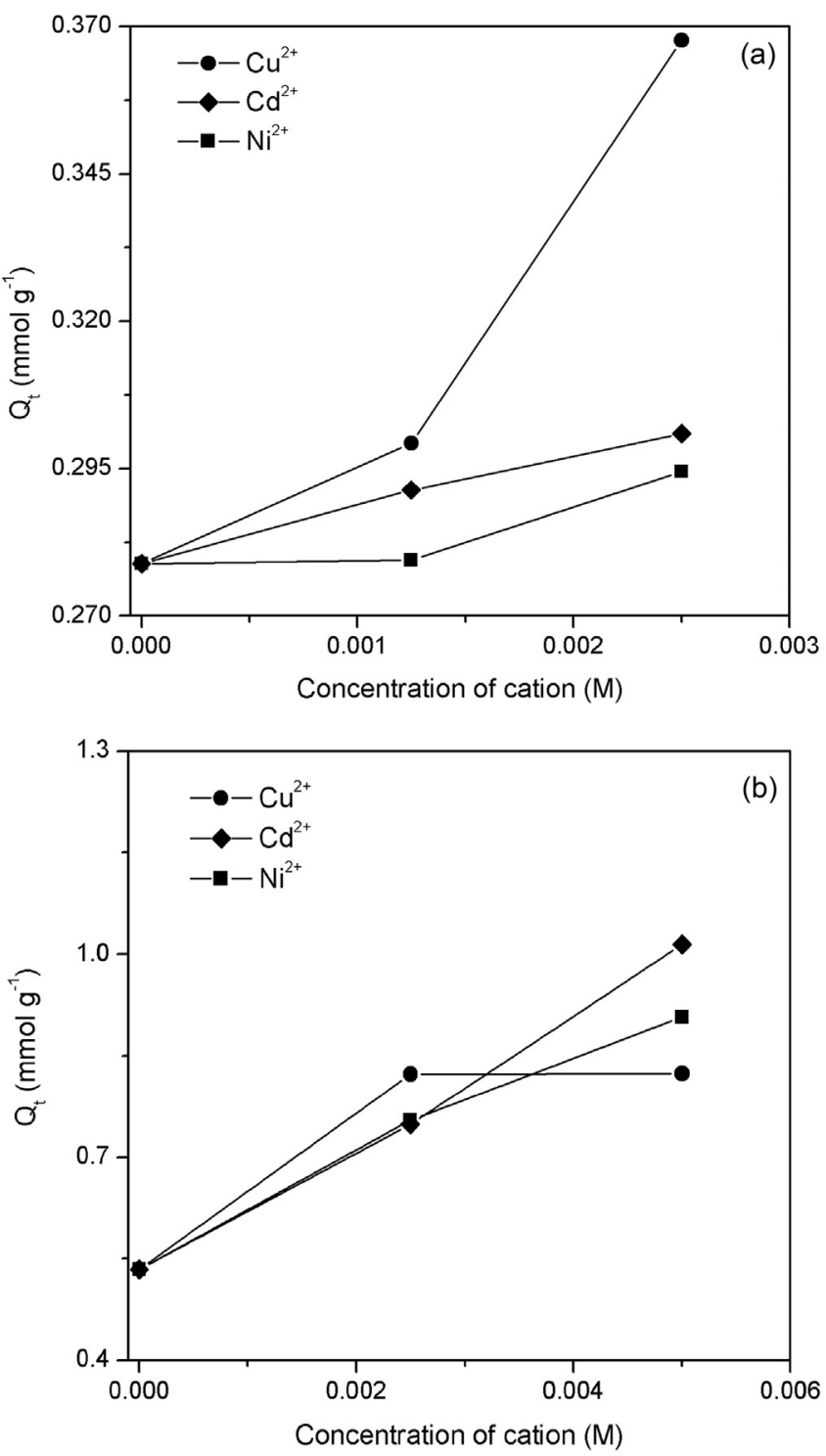

Fig. 11. Effects of background cations on $\operatorname{Re}(\mathrm{VII})$ (a) and $\mathrm{Mo}(\mathrm{VI})$ (b) sorption onto 10MAG-SGE60-deta (metal to cations concentration ratio $4: 1$ and 10:1, $C_{i}=0.01 \mathrm{M}$ for $\mathrm{Mo}(\mathrm{VI}), C_{i}=0.005 \mathrm{M}$ for $\operatorname{Re}(\mathrm{VII}), \mathrm{pH}=4, \mathrm{~T}=298 \mathrm{~K}, \mathrm{t}=3 \mathrm{~h}$ ).

earth metals (such as $\mathrm{Na}^{+}, \mathrm{Mg}^{2+}$ and $\mathrm{Ca}^{2+}$, i.e. the common ions in natural waters) were not used as background cations. Namely, amino-functionalized PGME is selective towards heavy metals and exhibits low (or none) sorption of alkali and alkaline earth metals.

As can be seen, the molybdate and perrhenate sorption is affected by the background anions and cations. The background anions compete with $\mathrm{Mo}(\mathrm{VI})$ and $\mathrm{Re}(\mathrm{VII})$ oxyanions for available binding sites on the 10MAG-SGE60-deta thus reducing the sorption of molybdate and perrhenate anions to some degree. The most pronounced effect i.e. significant reduction of sorption capacity was observed in the presence of $\mathrm{SO}_{4}^{2-}$. The competition of $\mathrm{Ni}^{2+}, \mathrm{Cd}^{2+}$ and $\mathrm{Cu}^{2+}$ with molybdate and perrhenate anions for adsorption sites of 10MAG-SGE60-deta resulted in the increase of $\mathrm{Mo}(\mathrm{VI})$ and $\mathrm{Re}(\mathrm{VII})$ sorption capacities.

\subsection{Effect of ionic strength}

The ionic strength of an aqueous solution is a very important parameter that influences the metal ions sorption at the solid-liquid

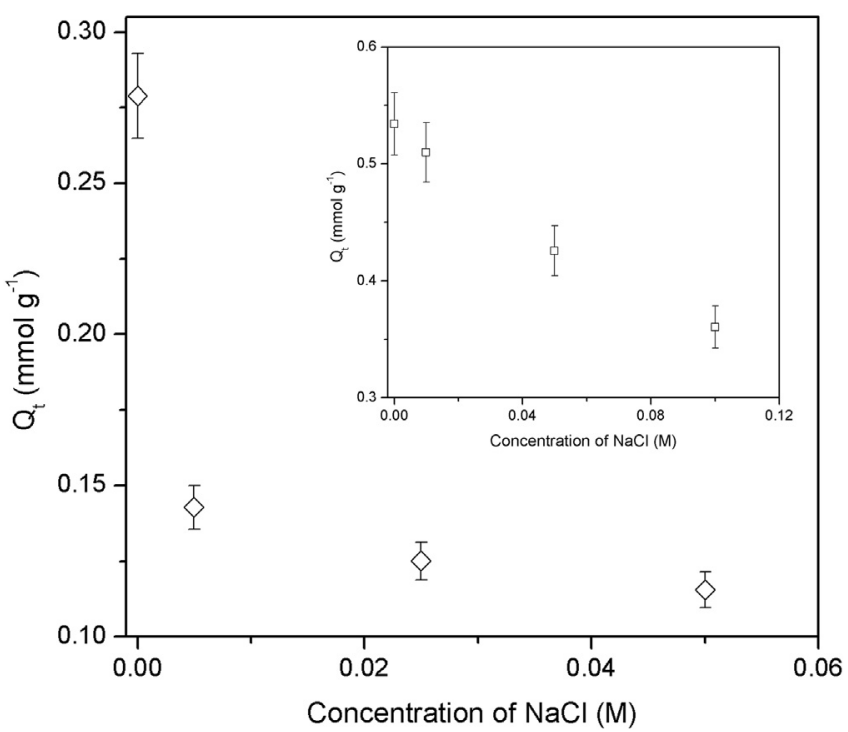

Fig. 12. Effect of $\mathrm{NaCl}$ concentration on $\mathrm{Re}(\mathrm{VII})$ and $\mathrm{Mo}(\mathrm{VI})$ (inset figure) sorption onto 10MAG-SGE60-deta $\left(C_{i}=0.01 \mathrm{M}\right.$ for $\mathrm{Mo}(\mathrm{VI}), C_{i}=0.005 \mathrm{M}$ for $\mathrm{Re}(\mathrm{VII})$, ratio of metal to $\mathrm{NaCl}$ concentration was $1: 1,1: 5$ and $1: 10, \mathrm{pH}=4, \mathrm{~T}=298 \mathrm{~K}, \mathrm{t}=3 \mathrm{~h}$ ). Standard errors are shown as vertical error bars.

interface [36]. The effect of ionic strength on $\mathrm{Mo}(\mathrm{VI})$ and $\operatorname{Re}(\mathrm{VII})$ sorption at different $\mathrm{NaCl}$ concentrations is shown in Fig. 12.

From the obtained equilibrium results a decrease in $\operatorname{Re}(\mathrm{VII})$ and $\mathrm{Mo}(\mathrm{VI})$ sorption onto 10MAG-SGE60-deta by increasing the ionic strength can be noticed, which could be ascribed to the decrease of positive charge of 10MAG-SGE60-deta surface, resulting in a lower attraction molybdenum and perrhenate anions [37].

\subsection{Sorption isotherms}

In order to determine model that is most appropriate to describe obtained equilibrium data, the sorption isotherms presented in

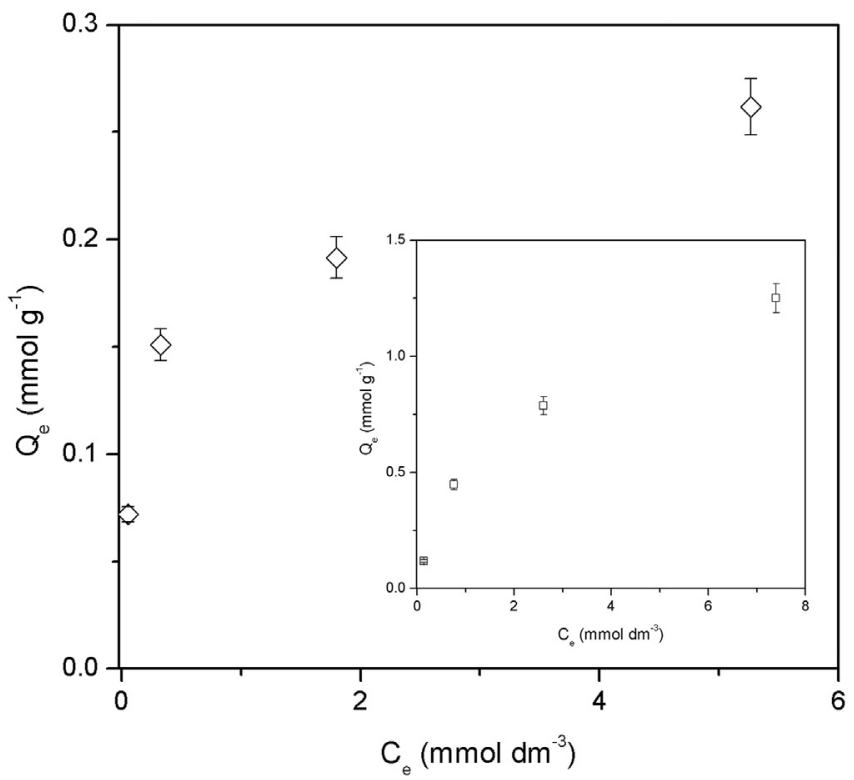

Fig. 13. Sorption isotherms for $\operatorname{Re}(\mathrm{VII})$ and $\mathrm{Mo}(\mathrm{VI})$ (inset figure) sorption on 10MAGSGE60-deta (conditions: $\mathrm{T}=298 \mathrm{~K}, \mathrm{pH}=4, \mathrm{t}=24 \mathrm{~h}, \mathrm{C}_{0}[\mathrm{Mo}(\mathrm{VI})]=0.002 ; 0.005 ; 0.01$ and $0.02 \mathrm{M}, \mathrm{C}_{0}[\operatorname{Re}(\mathrm{VII})]=0.001 ; 0.0025 ; 0.005$ and $\left.0.01 \mathrm{M}\right)$. Standard errors are shown as vertical error bars. 
Table 5

Langmuir, Freundlich and Tempkin adsorption isotherm parameters, correlation coefficients and $Q_{\max }$ values for $\mathrm{Mo}(\mathrm{VI})$ and $\mathrm{Re}(\mathrm{VII})$ sorption on 10MAG-SGE60-deta at $298 \mathrm{~K}$.

\begin{tabular}{llll}
\hline Models & Parameters & Metal & \\
\cline { 3 - 4 } & & $\mathrm{Mo}(\mathrm{VI})$ & $\operatorname{Re}(\mathrm{VII})$ \\
\hline \multirow{2}{*}{ Langmuir } & $Q_{\max }, \mathrm{mmol} \mathrm{g}^{-1}$ & 1.55 & 0.272 \\
& $K_{\mathrm{L}}, \mathrm{L} \mathrm{mmol}^{-1}$ & 0.514 & 2.89 \\
& $R^{2}$ & 0.986 & 0.986 \\
Freundlich & $n$ & 1.70 & 3.73 \\
& $K_{F},\left(\mathrm{mmol} \mathrm{g}^{-1}\right) /\left(\mathrm{mmol} \mathrm{L}^{-1}\right)^{1 / \mathrm{n}}$ & 0.433 & 0.172 \\
& $R^{2}$ & 0.977 & 0.956 \\
\multirow{2}{*}{ Tempkin } & $B_{T} \cdot 10^{3}$ & 8.94 & 63.5 \\
& $K_{T}, \mathrm{~L} \mathrm{mmol}^{-1}$ & 8.82 & 118 \\
& $R^{2}$ & 0.963 & 0.974 \\
\hline
\end{tabular}

Fig. 13 were analyzed with the linear Langmuir, Freundlich [38] and Tempkin [39] equations:

$\frac{C_{e}}{Q_{e}}=\frac{1}{Q_{\max } K_{L}}+\frac{C_{e}}{Q_{\max }}$

$\ln Q_{e}=\ln K_{F}+\frac{1}{n} \ln C_{e}$

$Q_{e}=\frac{R T}{b_{T}} \ln K_{T}+\frac{R T}{b_{T}} \ln C_{e}$

where $Q_{e}$ and $C_{e}$ are the amount of sorbed metal ions and equilibrium concentration of $\mathrm{Mo}(\mathrm{VI})$ and $\operatorname{Re}(\mathrm{VII}), Q_{\max }$ is the monolayer capacity of the adsorbent, $K_{\mathrm{L}}$ is the Langmuir isotherm constant, $K_{\mathrm{F}}$ and $n$ are the Freundlich constant and isotherm exponent, $b_{T}$ is constant related to the heat of adsorption from Tempkin isotherm model respectively.

The characteristics of Langmuir isotherm can be expressed by dimensionless constant called Langmuir equilibrium parameter $R_{L}$ given in Eq. (8):
$R_{L}=\frac{1}{1+K_{L} C_{0}}$

where $C_{0}$ is the initial concentration of $\mathrm{Mo}(\mathrm{VI})$ and $\operatorname{Re}(\mathrm{VII})$. The value of $R_{\mathrm{L}}$ indicates the type of the isotherm either to be unfavorable $\left(R_{\mathrm{L}}>1\right)$, linear $\left(R_{\mathrm{L}}=1\right)$, favorable $\left(0<R_{\mathrm{L}}<1\right)$ or irreversible $\left(R_{\mathrm{L}}=0\right)$.

Although the regression coefficients $\left(R^{2}\right)$ (Table 5) were high for all investigated linearized isotherm models, it can be concluded that Langmuir model is the most appropriate for the $\mathrm{Mo}(\mathrm{VI})$ and $\operatorname{Re}(\mathrm{VII})$ sorption onto 10MAG-SGE60-deta assuming monolayer adsorption at specific homogenous sites. The $\mathrm{R}_{\mathrm{L}}$ values for $\mathrm{Mo}(\mathrm{VI})$ and $\operatorname{Re}(\mathrm{VII})$ sorption were in the range of $0.09-0.60$ and 0.04 to 0.30 , respectively at $298 \mathrm{~K}$, indicating that the sorption of $\mathrm{Mo}(\mathrm{VI})$ and $\operatorname{Re}(\mathrm{VII})$ onto 10MAG-SGE60-deta is favorable. The maximum adsorption capacities for $\mathrm{Mo}(\mathrm{VI})$ and $\operatorname{Re}(\mathrm{VII})$ calculated by the Langmuir equation are given in Table 5 .

\subsection{FTIR analysis}

The FTIR spectra of the sample with adsorbed $\mathrm{Mo}(\mathrm{VI})$ and $\mathrm{Re}(\mathrm{VII})$ ions 10MAG-SGE60-deta/Mo(VI)/Re(VII) was recorded in the frequency range of $4000-400 \mathrm{~cm}^{-1}$ and presented in Fig. 14.

The bands for ester vibrations at $\sim 1720 \mathrm{~cm}^{-1}[v(C=0)]$, the bands characteristic for the crosslinked copolymer at $\sim 1160 \mathrm{~cm}^{-1}$ $[v(\mathrm{C}-\mathrm{O})], \sim 1450 \mathrm{~cm}^{-1}\left[\delta(\mathrm{CH})_{2}\right], 2990 \mathrm{~cm}^{-1}, \sim 2950 \mathrm{~cm}^{-1}$ and $2830 \mathrm{~cm}^{-1}$ [methyl and methylene stretching vibrations, $v(\mathrm{C}-\mathrm{H})$ ] as well as the characteristic peak for Fe-O vibrations at $\sim 590 \mathrm{~cm}^{-1}$ can be observed in 10MAG-SGE60-deta/Mo(VI)/Re(VII) spectra [40]. The disappearance of the peak at $1580 \mathrm{~cm}^{-1}[\delta(\mathrm{NH})]$, as well as the shift of the $\delta\left(\mathrm{NH}_{2}\right)$ peak from $\sim 1670 \mathrm{~cm}^{-1}$ to $\sim 1650 \mathrm{~cm}^{-1}$ observed in the 10MAG-SGE60-deta/Mo(VI)/Re(VII) spectra clearly indicate the $\mathrm{Mo}(\mathrm{VI})$ and $\operatorname{Re}(\mathrm{VII})$ binding to amino-groups of 10MAG-SGE60-deta. According to Golcuk et al. the binding with the metal alters the hybridization type around nitrogen and weakens $\mathrm{NH}$ bond [41]. According to Jin and Bai, this can suggest that $\mathrm{O}$

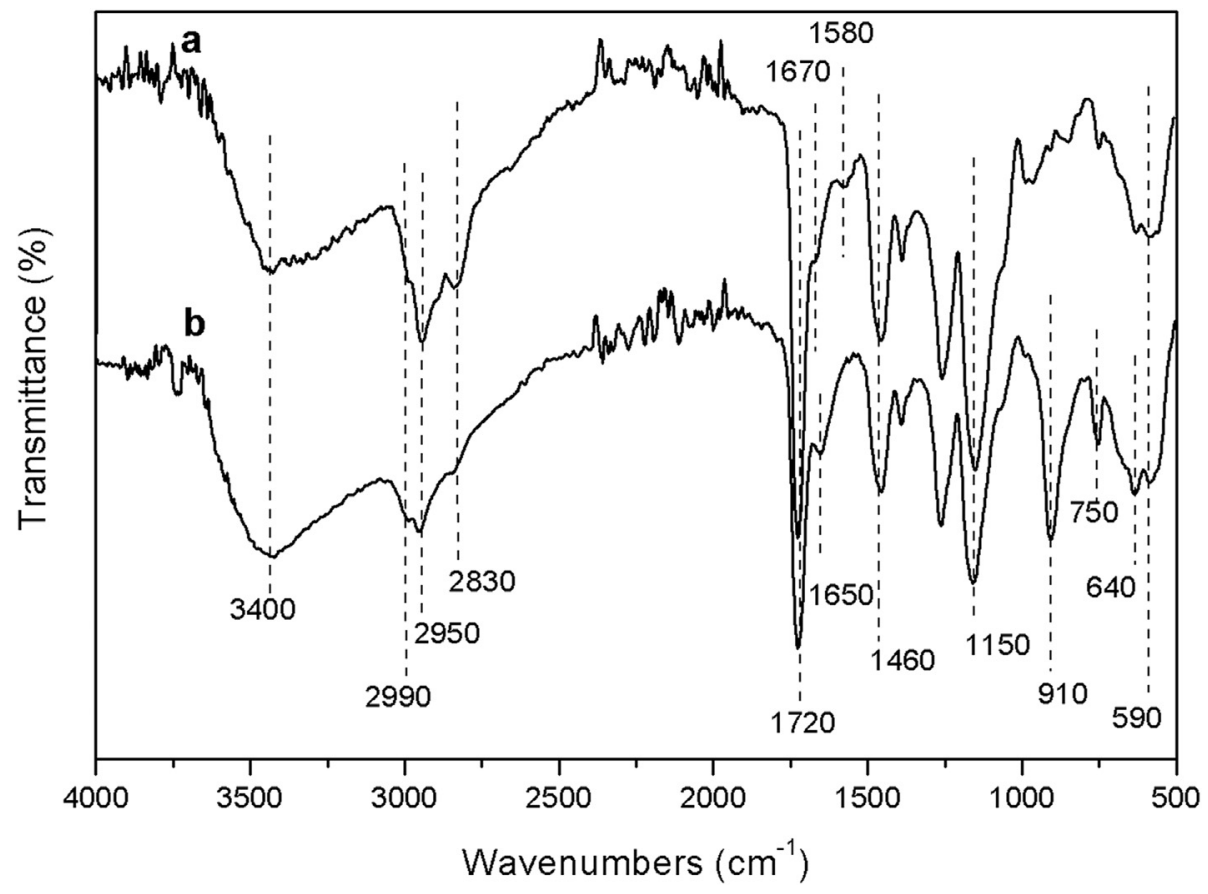

Fig. 14. FTIR spectra of (a) 10MAG-SGE60-deta and (b) 10MAG-SGE60-deta/Mo(VI)/Re(VII). 

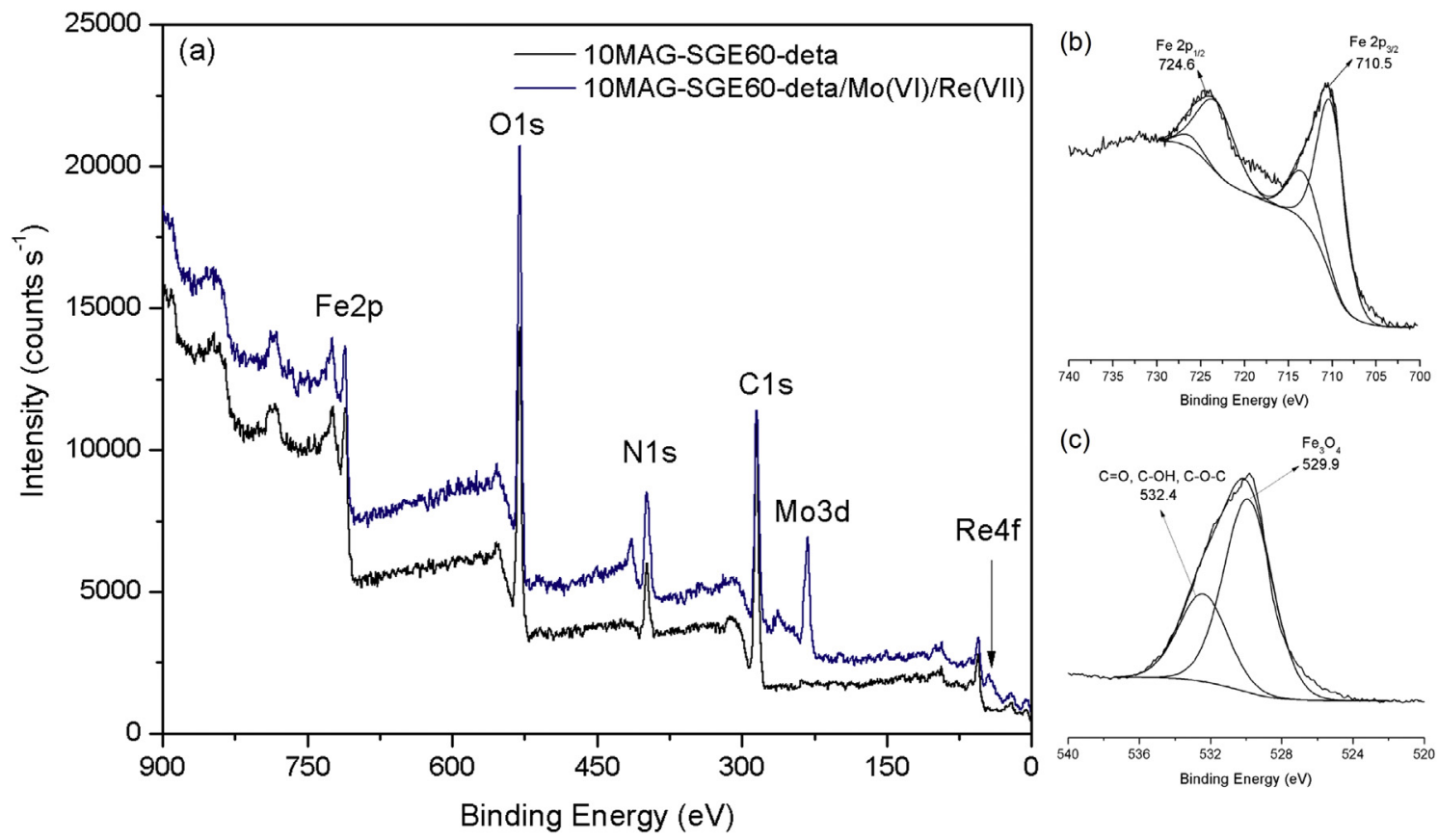

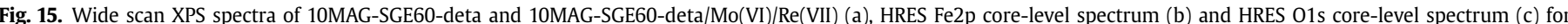
10MAG-SGE60-deta.
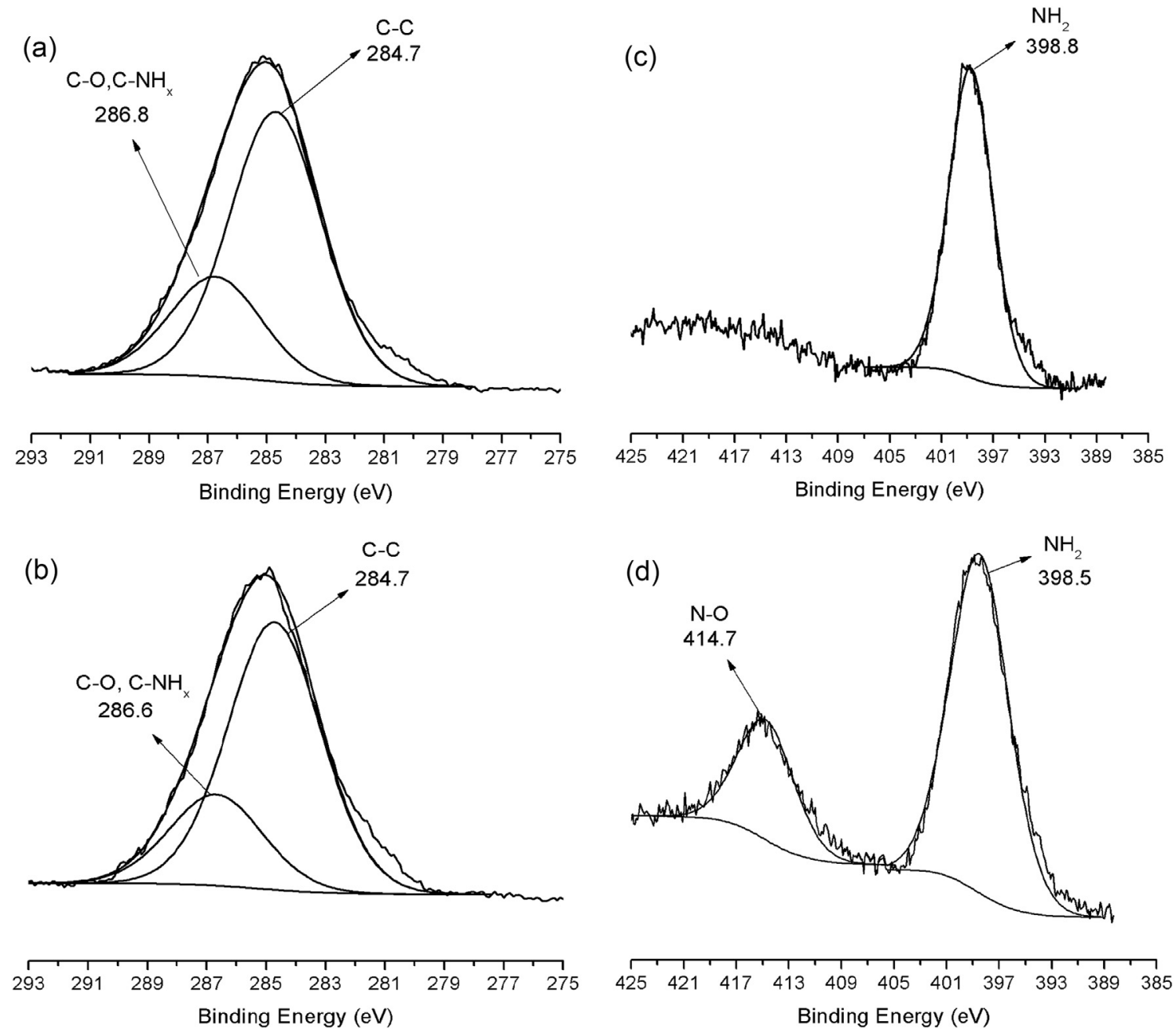

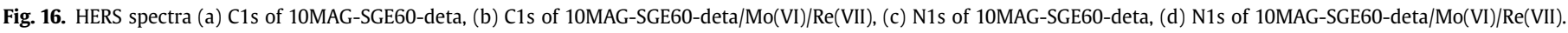


atoms in - $\mathrm{OH}$ groups might also be involved in metal ions sorption, yet in a lower extent then $\mathrm{N}$ atoms [42]. The most significant part of the FTIR spectra regarding $\mathrm{Mo}(\mathrm{VI})$ and $\mathrm{Re}(\mathrm{VII})$ binding is positioned in the $1000-700 \mathrm{~cm}^{-1}$ region (Me-O absorption bands). The clear evidence of the $\mathrm{Mo}(\mathrm{VI})$ and $\mathrm{Re}(\mathrm{VII})$ binding to 10MAG-SGE60-deta/ $\mathrm{Mo}(\mathrm{VI}) / \operatorname{Re}(\mathrm{VII})$ is the appearance of strong $\mathrm{v}(\mathrm{Me}=\mathrm{O})$ band detected at $910 \mathrm{~cm}^{-1}$ and medium $\mathrm{v}(\mathrm{Me}-\mathrm{O})$ bands at $750 \mathrm{~cm}^{-1}$ and $640 \mathrm{~cm}^{-1}[43,44]$.

\subsection{XPS analysis}

XPS analysis was used to investigate the changes in the elemental and chemical composition and functional groups of the samples surface prior and after sorption of $\mathrm{Mo}(\mathrm{VI})$ and $\operatorname{Re}(\mathrm{VII})$ ions.

Fig. 15(a) illustrates the XPS wide scan spectra of 10MAG-SGE60deta and 10MAG-SGE60-deta/Mo(VI)/Re(VII) over a wide binding energy range from 0 to $900 \mathrm{eV}$ showing surface elemental composition. As expected, $\mathrm{C} 1 \mathrm{~s}, \mathrm{O} 1 \mathrm{~s}, \mathrm{~N} 1 \mathrm{~s}$ and Fe2p were identified in

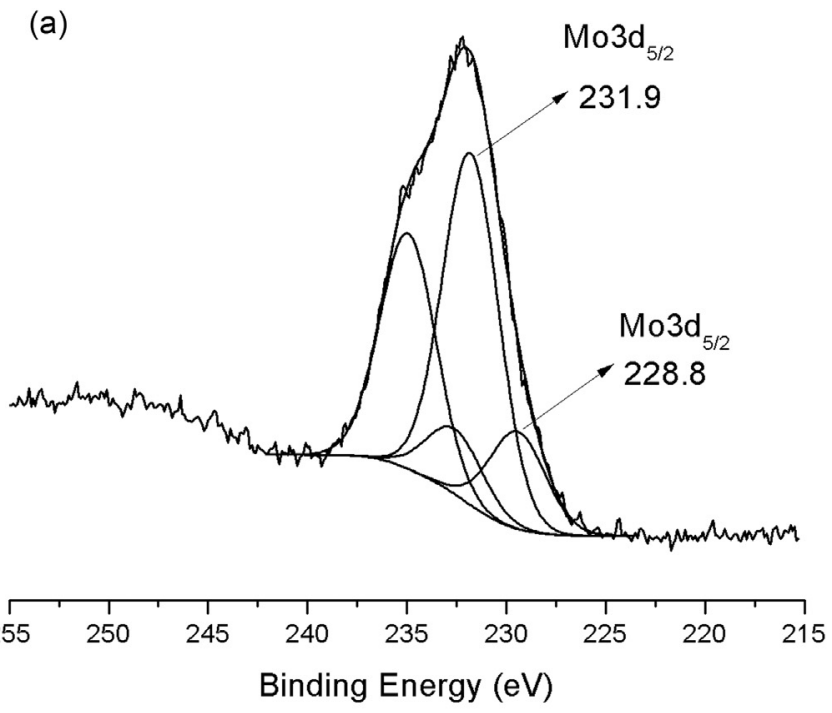

(b)

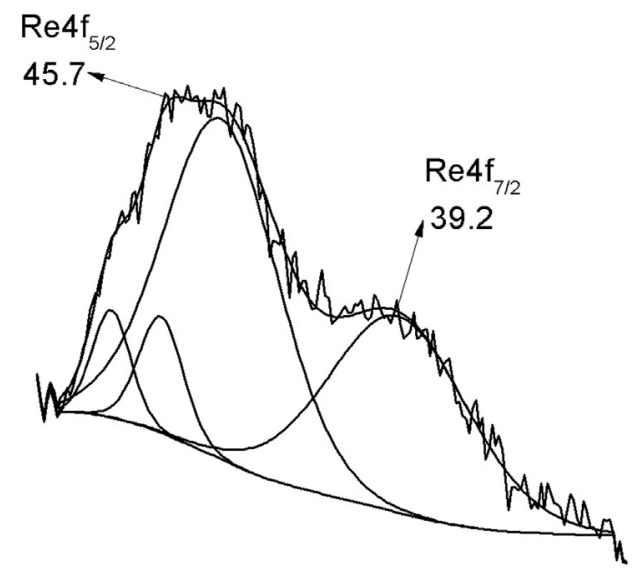

\begin{tabular}{rllll|l|l|}
\hline 54 & 50 & 46 & 42 & 38 & 34 & 30 \\
& & & \\
& & Binding Energy (eV) & &
\end{tabular}

Fig. 17. HERS spectra (a) Mo3d and (b) Re4f of 10MAG-SGE60-deta/Mo(VI)/Re(VII). the XPS wide scan spectra of sample 10MAG-SGE60-deta. The presence of Mo3d and Re4f peaks indicates molybdenum and rhenium ions bonding with reactive sites onto the sorbent.

The Fe2p core-level spectrum of sample 10MAG-SGE60-deta (Fig. 15(b)) shows two peaks at around $710.5 \mathrm{eV}$ and $724.6 \mathrm{eV}$ which are related to $\mathrm{Fe} 2 \mathrm{p}_{3 / 2}$ and $\mathrm{Fe} 2 \mathrm{p}_{1 / 2}$ respectively, indicating the formation of $\mathrm{Fe}_{3} \mathrm{O}_{4}$ [45]. Fig. 15(c) shows the 01s high resolution (HRES) spectrum of sample 10MAG-SGE60-deta. The O1s core-level spectrum was fitted into two components having binding energies (BEs) at $529.9 \mathrm{eV}$ for $\mathrm{Fe}_{3} \mathrm{O}_{4}$ (O1s lattice oxide) [46] and peak at $532.4 \mathrm{eV}$ which corresponds to $\mathrm{C}=\mathrm{O}, \mathrm{C}-\mathrm{OH}$ and $\mathrm{C}-\mathrm{O}-\mathrm{C}$.

In order to reveal more about the interaction between metal ions and amino groups, HRES spectra of C1s, N1s (Fig. 16), Mo3d (Fig. 17(a)) and Re4f (Fig. 17(b)) were measured. The peaks of both samples in the C1s core-level spectrum (Fig. 16(a) and (b)) were fitted into two components at 284.7 and $286.8 \mathrm{eV}$ corresponding to $\mathrm{C}-\mathrm{C}$ and $\mathrm{C}-\mathrm{O} / \mathrm{C}-\mathrm{NH}_{\mathrm{x}}$, respectively $[47,48]$. It was observed that the intensity of $\mathrm{C}-\mathrm{O} / \mathrm{C}-\mathrm{NH}_{\mathrm{X}}$ location of the peak had a shift to $286.6 \mathrm{eV}$, which indicates that $\mathrm{C}-\mathrm{NH}_{\mathrm{X}}$ is involved in the sorption of metal ions onto the adsorbent. The N1s core-level spectrum of sample 10MAGSGE60-deta (Fig. 16(c)) has a nitrogen peak positioned at $398.8 \mathrm{eV}$ assigned to non-protonated $\left(\mathrm{NH}_{2}\right)$ amino groups [48]. The spectra of 10MAG-SGE60-deta/Mo(VI)/Re(VII) (Fig. 16(d)) exhibited two peaks, i.e. peak for amino group at $398.5 \mathrm{eV}$ and a new peak at $414.7 \mathrm{eV}$ assigned to $\mathrm{N}-\mathrm{O}$ bond [7].

The Mo3d core-level spectrum of sample (Fig. 17(a)) was fitted into two components for Mo3d $\mathrm{d}_{5 / 2}$ at $231.8 \mathrm{eV}$ and $229.4 \mathrm{eV}$ indicating molybdenum binding with reactive sites onto the 10MAGSGE60-deta surface. The first peak can be ascribed to $\mathrm{Mo}^{5+}$ [49], and the second one to $\mathrm{MoO}_{2}$ phase [50].

The Re4f narrow scan XPS spectra of 10MAG-SGE60-deta/ $\mathrm{Mo}(\mathrm{VI}) / \operatorname{Re}(\mathrm{VII})$ (Fig. 17(b)) shows $\operatorname{Re} 4 \mathrm{f}_{5 / 2}$ and $\operatorname{Re} 4 \mathrm{f}_{7 / 2}$ doublet positioned at $45.7 \mathrm{eV}$ and $39.2 \mathrm{eV}$ indicating perrhenate binding with reactive sites onto the 10MAG-SGE60-deta surface. The more intense $\operatorname{Re}_{4 \mathrm{f}_{7 / 2}}$ peak can be deconvoluted into three components at $44.8,46.6$ and $48.1 \mathrm{eV}$ which indicates the complexation and the existence of rhenium different oxidation states in the sample [4,51-53].

\section{Conclusion}

In this study, magnetic macroporous crosslinked copolymers of glycidyl methacrylate (GMA) and ethylene glycol dimethacrylate (EGDMA) samples (mPGME) with different magnetite content were synthesized and functionalized with diethylene triamine (mPGMEdeta). Samples were characterized by elemental analysis, mercury porosimetry, scanning electron microscopy with energy-dispersive X-ray spectroscopy, transmission electron microscopy and SQUID magnetometry. The influence of $\mathrm{pH}$, ionic strength and possible interfering of cations and anions was investigated. Obtained results indicate that $92 \%$ of $\mathrm{Re}(\mathrm{VII})$ and $98 \%$ of $\mathrm{Mo}(\mathrm{VI})$ were sorbed at $\mathrm{pH} 2$. It was observed that $\mathrm{Mo}(\mathrm{VI})$ and $\mathrm{Re}(\mathrm{VII})$ sorption is affected by the background anions and cations, as well as ionic strength. Equilibrium data were analyzed with Langmuir, Freundlich and Tempkin adsorption isotherm models. Langmuir model is the most appropriate for the $\mathrm{Mo}(\mathrm{VI})$ and $\mathrm{Re}(\mathrm{VII})$ sorption onto 10MAG-SGE60-deta assuming monolayer adsorption at specific homogenous sites. FTIR and XPS analysis spectra confirmed $\mathrm{Mo}(\mathrm{VI})$ and $\mathrm{Re}(\mathrm{VII})$ binding to amino-groups in mPGME-deta, suggesting that $\mathrm{O}$ atoms in $-\mathrm{OH}$ groups might also be involved in metal ions sorption. SEM-EDS results show that although predominantly present at the particle surface, the iron nanoparticles were also embedded in the bulk to a certain extent. The TEM images show a uniform distribution of dark magnetic nanoparticles throughout the gray copolymer matrix. The magnetization measurements showed superparamagnetic 
behavior with negligible hysteresis loop and an expected increase in the magnetization value with increasing magnetite content. The ratio of saturation magnetization values obtained for 2MAG-SGE60 and 10MAG-SGE60 close to 1:5 suggests that nominal magnetite content has been achieved as well as that magnetite nanoparticles do not agglomerate within mPGME particles thus preserving favorable superparamagnetic behavior.

\section{Acknowledgements}

This work was supported by the Ministry of Education, Science and Technological Development of the Republic of Serbia (Projects III 43009, III 45015, ON 172062 and OI 172057).

\section{References}

[1] R. Navarro, J. Guzmán, I. Saucedo, J. Revilla, E. Guibal, Recovery of metal ions by chitosan: sorption mechanisms and influence of metal speciation, Macromol. Biosci. 3 (2003) 552-561.

[2] C. Namasivayam, D. Sangeetha, Removal of molybdate from water by adsorption onto $\mathrm{ZnCl}_{2}$ activated coir pith carbon, Bioresour. Technol. 97 (2006) 1194-1200.

[3] A.J. Sherman, R.H. Tuffias, R.B. Kaplan, The properties and applications of rhenium produced by CVD, Jom 43 (1991) 20-23.

[4] Z. Lou, L. Wan, C. Guo, S. Zhang, W. Shan, Y. Xiong, Quasi-complete separation $\mathrm{Re}(\mathrm{VII})$ from Mo(VI) onto magnetic modified cross-linked chitosan crab shells gel by using kinetics methods, Ind. Eng. Chem. Res. 54 (2015) 1333-1341.

[5] A. Naumov, Rhythms of rhenium, Russ. J. Non-Ferrous Met. 48 (2007) $418-423$.

[6] W. Shan, Q. Zhang, Y. Shu, W. Wang, H. Ru, Y. Xiong, Aminopropyl-grafted various silica mesostructures for adsorption of molybdenum ions from Recontaining effluent, Adsorption 22 (2016) 859-869.

[7] W. Shan, Y. Shu, H. Chen, D. Zhang, W. Wang, H. Ru, Y. Xiong, The recovery of molybdenum(VI) from rhenium(VII) on amino-functionalized mesoporous materials, Hydrometallurgy 165 (2016) 251-260.

[8] M. Jia, H. Cui, W. Jin, L. Zhu, Y. Liu, J. Chen, Adsorption and separation of rhenium(VII) using $\mathrm{N}$-methylimidazolium functionalized strong basic anion exchange resin, J. Chem. Technol. Biotechnol. 88 (2013) 437-443.

[9] Y. Li, Q. Wang, Q. Li, Z. Zhang, L. Zhang, X. Liu, Simultaneous speciation of inorganic rhenium and molybdenum in the industrial wastewater by aminofunctionalized nano-SiO 2 , J. Taiwan Inst. Chem. Eng. 55 (2015) 126-132.

[10] T. Lee, H. Lim, Y. Lee, J.W. Park, Use of waste iron metal for removal of $\mathrm{Cr}(\mathrm{VI})$ from water, Chemosphere 53 (2003) 479-485.

[11] D. Duranoĝlu, I.G. Buyruklardan Kaya, U. Beker, B.F. Şenkal, Synthesis and adsorption properties of polymeric and polymer-based hybrid adsorbent for hexavalent chromium removal, Chem. Eng. J. 181-182 (2012) 103-112.

[12] M. Xie, L. Zeng, Q. Zhang, Y. Kang, H. Xiao, Y. Peng, X. Chen, J. Luo, Synthesis and adsorption behavior of magnetic microspheres based on chitosan/organic rectorite for low-concentration heavy metal removal, J. Alloys Compd. 647 (2015) 892-905.

[13] T.H. Chung, H.C. Pan, W.C. Lee, Preparation and application of magnetic poly(styrene-glycidyl methacrylate) microspheres, J. Magn. Magn. Mater. 31 (2007) 36-40.

[14] D. Horák, E. Pollert, M. Trchová, J. Kovářová, Magnetic poly(glycidyl methacrylate)-based microspheres prepared by suspension polymerization in the presence of modified $\mathrm{La}_{0.75} \mathrm{Sr}_{0.25} \mathrm{MnO}_{3}$ nanoparticles, Eur. Polym. J. 45 (2009) 1009-1016.

[15] S.M. Jovanovic, A. Nastasovic, N.N. Jovanovic, K. Jeremic, Z. Savic, The influence of inert component composition on the porous structure of glycidyl methacrylate/ethylene glycol dimethacrylate copolymers, Die Angew. Makromol. Chem. 219 (1994) 161-168.

[16] N. Miletić, Z. Vuković, A. Nastasović, K. Loos, Effect of Candida Antarctica lipase B immobilization on the porous structure of the carrier, Macromol. Biosci. 11 (2011) 1537-1543.

[17] Z.P. Sandić, A.B. Nastasović, N.P. Jović-Jovičić, A.D. Milutinović-Nikolić, D.M. Jovanović, Sorption of textile dye from aqueous solution by macroporous amino-functionalized copolymer, J. Appl. Polym. Sci. 121 (2011) 234-242.

[18] R.V. Hercigonja, D.D. Maksin, A.B. Nastasović, S.S. Trifunović, P.B. Glodić, A.E. Onia, Adsorptive removal of technetium 99 using macroporous poly(GMA-co-EGDMA) modified with diethylene triamine, J. Appl. Polym. Sci. 123 (2012) 1273-1282.

[19] D.D. Maksin, A.B. Nastasović, A.D. Milutinović-Nikolić, L.T. Suručić, Z.P. Sandić, R.V. Hercigonja, A.E. Onjia, Equilibrium and kinetics study on hexavalent chromium adsorption onto diethylene triamine grafted glycidyl methacrylate based copolymers, J. Hazard. Mater. 209-210 (2012) 99-110.

[20] A. Nastasović, S. Jovanović, D. Dordević, A. Onjia, D. Jakovljević, T. Novaković Metal sorption on macroporous poly(GMA-co-EGDMA) modified with ethylene diamine, React. Funct. Polym. 58 (2004) 139-147.

[21] A. Nastasović, D. Jakovljević, Z. Sandić, D. Đorđević, L. Malović, S. Kljajević, J. Marković, A. Onjia, Amino-functionalized glycidyl methacrylate based macroporous copolymers as metal ion sorbents, in: M.I. Barroso (Ed.), React, Funct. Polym. Res. Adv, Nova Science Publishers Inc, New York, 2007, pp. 79-112.

[22] P.A. Webb, C. Orr, Analytical Methods in Fine Particle Technology, Micromeritics Instrument Corp, Norcross, Georgia, United States, 1997.

[23] B.H. Hameed, I.A.W. Tan, A.L. Ahmad, Adsorption isotherm, kinetic modeling and mechanism of 2,4,6-trichlorophenol on coconut husk-based activated carbon, Chem. Eng. J. 144 (2008) 235-244.

[24] H. Chen, G. Dai, J. Zhao, A. Zhong, J. Wu, H. Yan, Removal of copper(II) ions by a biosorbent-Cinnamomum camphora leaves powder, J. Hazard. Mater. 177 (2010) 228-236.

[25] B.F. Şenkal, E. Yavuz, Crosslinked poly(glycidyl methacrylate)-based resin for removal of mercury from aqueous solutions, J. Appl. Polym. Sci. 101 (2006) $348-352$.

[26] F. Radovanović, A. Nastasović, T. Tomković, D. Vasiljević-Radović, A. Nešić, S. Veličković, A. Onjia, Novel membrane adsorbers incorporating functionalized polyglycidyl methacrylate, React. Funct. Polym. 77 (2014) 1-10.

[27] B.F. Şenkal, N. Biçak, Glycidyl methacrylate based polymer resins with diethylene triamine tetra acetic acid functions for efficient removal of $\mathrm{Ca}$ (II) and $\mathrm{Mg}(\mathrm{II})$, React. Funct. Polym. 49 (2001) 151-157.

[28] O. Duman, S. Tunç, B.K. Bozoğlan, T.G. Polat, Removal of triphenylmethane and reactive azo dyes from aqueous solution by magnetic carbon nanotubeк-carrageenan- $\mathrm{Fe}_{3} \mathrm{O}_{4}$ nanocomposite, J. Alloys Compd. 687 (2016) 370-383.

[29] G. Bayramoğlu, M. Yakup Arica, Adsorption of $\mathrm{Cr}(\mathrm{VI})$ onto PEI immobilized acrylate-based magnetic beads: isotherms, kinetics and thermodynamics study, Chem. Eng. J. 139 (2008) 20-28.

[30] A. Pourjavadi, A. Abedin-Moghanaki, Ultrafast and efficient removal of cationic dyes using a magnetic nanocomposite based on functionalized crosslinked poly(methylacrylate), React. Funct. Polym. 105 (2016) 95-102.

[31] Y. Tai, L. Wang, J. Gao, W.A. Amer, W. Ding, H. Yu, Synthesis of $\mathrm{Fe}_{3} \mathrm{O}_{4} @$ pol$\mathrm{y}$ (methylmethacrylate-co-divinylbenzene) magnetic porous microspheres and their application in the separation of phenol from aqueous solutions, J. Colloid Interface Sci. 360 (2011) 731-738.

[32] A.A. Atia, A.M. Donia, H.A. Awed, Synthesis of magnetic chelating resins functionalized with tetraethylenepentamine for adsorption of molybdate anions from aqueous solutions, J. Hazard. Mater. 155 (2008) 100-108.

[33] Z.P. Sandić, M.J. Zunić, D.D. Maksin, A.D. Milutinović-Nikolić, A.R. Popović, D.M. Jovanović, A.B. Nastasović, Glycidyl methacrylate macroporous copolymer grafted with diethylene triamine as sorbent for Reactive Black 5, Hem. Ind. 68 (2014) 685-699.

[34] International Atomic Energy Agency, Application of Ion Exchange Processes for the Treatment of Radioactive Waste and Management of Spent Ion Exchangers, 2002, in: http://www-pub.iaea.org/books/IAEABooks/6221/ Application-of-Ion-Exchange-Processes-for-Treatment-of-RadioactiveWaste-and-Management-of-Spent-Ion-Exchangers.

[35] A.M. Mahmoud, F.A. Ibrahim, S.A. Shaban, N.A. Youssef, Adsorption of heavy metal ion from aqueous solution by nickel oxide nano catalyst prepared by different methods, Egypt. J. Pet. 24 (2015) 27-35.

[36] T.S. Anirudhan, M. Ramachandran, Synthesis and characterization of amidoximated polyacrylonitrile/organobentonite composite for Cd(II), Zn(II), and $\mathrm{Cd}(\mathrm{II})$ adsorption from aqueous solutions and industry wastewaters, Ind. Eng. Chem. Res. 47 (2008) 6175-6184.

[37] M. Ernst, A. Bismarck, J. Springer, M. Jekel, Zeta-potential and rejection rates of a polyethersulfone nanofiltration membrane in single salt solutions, J. Memb. Sci. 165 (2000) 251-259.

[38] M.A. Riswan Ahamed, R. Subha, D. Jeyakumar, A.R. Burkanudeen, Separation of metal ions by the influence of a cation-exchange terpolymer involving 2amino-6-nitrobenzothiazole-ethylenediamine-formaldehyde, Polym. Int. 64 (2015) 126-137.

[39] Ö. Yunus, Kinetics of adsorption of dyes from aqueous solution using activated carbon prepared from waste apricot, J. Hazard. Mater. 137 (2006) 1719-1728.

[40] J. Coates, Interpretation of infrared spectra, a practical approach, in: R.A. Meyers (Ed.), Encycl. Anal. Chem, John Wiley and Sons Ltd, 2000, pp. 10815-10837.

[41] K. Golcuk, A. Altun, M. Kumru, Thermal studies and vibrational analyses of mmethylaniline complexes of $\mathrm{Zn}(\mathrm{II}), \mathrm{Cd}(\mathrm{II})$ and $\mathrm{Hg}(\mathrm{II})$ bromides, Spectrochim. Acta 59 (2003) 1841-1847.

[42] L. Jin, R. Bai, Mechanisms of lead adsorption on chitosan/PVA hydrogel beads, Langmuir 18 (2002) 9765-9770.

[43] N. AlHokbany, Spectroscopic investigation and density functional theory calculations of mercaptobenzothiazole and mercaptobenzimidazole ligands and their rhenium complexes, Open J. Inorg. Chem. 1 (2011) 23-32.

[44] E. Guibal, C. Milot, O. Eterradossi, C. Gauffier, A. Domard, Study of molybdate ion sorption on chitosan gel beads by different spectrometric analyses, Int. J. Biol. Macromol. 24 (1999) 49-59.

[45] S.Y. Wu, R.B. Ladani, J. Zhang, A.J. Kinloch, Z.H. Zhao, J. Ma, X.H. Zhang A.P. Mouritz, K. Ghorbani, C.H. Wang, Epoxy nanocomposites containing magnetite-carbon nanofibers aligned using a weak magnetic field, Polymer 68 (2015) 25-34

[46] M.C. Biesinger, B.P. Payne, A.P. Grosvenor, L.W.M. Lau, A.R. Gerson, R.S.C. Smart, Resolving surface chemical states in XPS analysis of first row transition metals, oxides and hydroxides: $\mathrm{Cr}$, Mn, Fe, Co and Ni, Appl. Surf. Sci. 257 (2011) 2717-2730.

[47] B.P. Payne, M.C. Biesinger, N.S. McIntyre, The study of polycrystalline nickel metal oxidation by water vapour, J. Electron Spectros. Relat. Phenom. 175 
(2009) 55-65.

[48] A.B. Nastasović, B.M. Ekmeščić, Z.P. Sandić, D.V. Ranđelović, M. Mozetič, A. Vesel, A.E. Onjia, Mechanism of $\mathrm{Cu}(\mathrm{II}), \mathrm{Cd}(\mathrm{II})$ and $\mathrm{Pb}$ (II) ions sorption from aqueous solutions by macroporous poly(glycidyl methacrylate-co-ethylene glycol dimethacrylate), Appl. Surf. Sci. 385 (2016) 605-615.

[49] J. Baltrusaitis, B. Mendoza-Sanchez, V. Fernandez, R. Veenstra, N. Dukstiene, A. Roberts, N. Fairley, Generalized molybdenum oxide surface chemical state XPS determination via informed amorphous sample model, Appl. Surf. Sci. 326 (2015) 151-161.

[50] D.D.O. Scanlon, G.G.W. Watson, D.J. Payne, G.R. Atkinson, R.G. Egdell, D.S.L. Law, Theoretical and experimental study of the electronic structures of
$\mathrm{MoO}_{3}$ and $\mathrm{MoO}_{2}$, J. Phys. Chem. C 114 (2010) 4636-4645.

51] M.T. Greiner, T.C.R. Rocha, B. Johnson, A. Klyushin, A. Knop-Gericke, R. Schlögl, The oxidation of rhenium and identification of rhenium oxides during catalytic partial oxidation of ethylene: an in-situ xps study, Z. Fur Phys. Chem. 228 (2014) 521-541.

[52] K.M. Babu, M.R. Mucalo, XPS studies of freshly prepared rhenium nanoparticle dispersions from hydrazinium hydrate and borohydride reduction of hexachlororhenate solutions, J. Mater. Sci. Lett. 22 (2003) 1755-1757.

[53] J. Okal, W. Tylus, L. Kepinski, XPS study of oxidation of rhenium metal on $\gamma$ $\mathrm{Al}_{2} \mathrm{O}_{3}$ support, J. Catal. 225 (2004) 498-509. 